\title{
A Novel Cooperative Controller for Inverters of Smart Hybrid AC/DC Microgrids
}

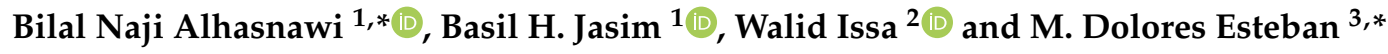 \\ 1 Electrical Engineering Department, University of Basrah, Basrah 61001, Iraq; hanbas632@gmail.com \\ 2 Electrical Engineering Department, Sheffield Hallam University, Pond Street, Sheffield S1 1WB, UK; \\ walid.issa@shu.ac.uk \\ 3 Civil Engineering Department, Hydraulics, Energy and Environment/Professor Aranguren 3, \\ Universidad Politécnica de Madrid (UPM), CP 28040 Madrid, Spain \\ * Correspondence: bilalnaji11@yahoo.com (B.N.A.); mariadolores.esteban@upm.es (M.D.E.); \\ Tel.: +964-78090985 (B.N.A.)
}

Received: 13 July 2020; Accepted: 1 September 2020; Published: 3 September 2020

\begin{abstract}
This paper presents a novel cooperative control technique concerning fully-distributed AC/DC microgrids. Distributed generation based on inverters has two types, i.e., Current Source Inverter (CSI), also referred to as PQ inverter, and Voltage Source Inverter (VSI). Both inverter forms have a two-layer coordination mechanism. This paper proposes a design method for the digital Proportional-Resonant (PR) controller that regulates the current inside an inverter. The inverters will improve the voltage quality of the microgrid while maintaining the average voltage of buses at the same desired level. There is comprehensive detail on the computations specific to resonant and proportional gains and digital resonance path coefficients. The paper includes a digital PR controller design and its analysis in the frequency domain. The analysis is based on the w-domain. The main contribution of this paper is the proposed method, which not only focuses on the transient response but also improves the steady-state response which smoothens the voltage; furthermore, all inverters are effectively involved to increase the capacity of the microgrid for better power management. The suggested cooperative control technique is used on an IEEE 14-bus system having fully distributed communication. The convincing outcomes indicate that the suggested control technique is an effectual means of regulating the microgrid's voltage to obtain an evener and steady voltage profile. The microgrid comprises distributed resources and is used as the primary element to analyse power flow and quality indicators associated with a smart grid. Lastly, numerical simulation observations are utilised for substantiating the recommended algorithm.
\end{abstract}

Keywords: IEEE 14-bus microgrid; converters; proportional resonant controller; notch filters; inverters

\section{Introduction}

The AC/DC converters and output filters are a foremost and essential technology for linking Renewable Energy Sources (RES) and the electric grid. The converter enables energy transaction between the grid and RES in an appropriate, secure and dependable way. These types of DC-AC converters are informally called grid-tied inverters or Grid-Connected Inverters (GCI).

The smart grid is the newest generation of the conventional power system grids which rely on the two-way power flow and information transfer competencies [1-7]. A traditional grid comprises control centres, power generation, transmission, distribution, and consumers [8]. Presently, with the progression of new digital technologies, like micro processed systems, and developments in power electronics, several applications have been deployed in the smart grid, particularly in the formulation of electronic energy converters and controllers. Of late, academics have made noteworthy contributions 
which have caused a significant effect on these domains, chiefly aimed at data acquirement, automation, and regulation of microgrids [9]. The microgrids do not merely assimilate the distributed generation with the utility grid in a dependable and tidy manner but also offer greater dependability in its capability to function despite natural phenomena and dynamic distribution grids, consequently causing reduced energy losses in transmission and dissemination and saving the time consumed in building and investment [10-14].

In literature, authors in [15] suggested an AC/DC hybrid microgrid comprising wind, supercapacitors, and hydrogen-based energy to regulate the power fed to the microgrid. This DC system has all energy sources coupled to a shared DC-bus, which is then linked with the grid using a primary inverter. How the variable load demand affects the system has not been analysed. One more hybrid DC/AC microgrid structure comprising photovoltaic and fuel cells were recommended in [16]. A synchronised function of unit power control and feeder flow control was formulated for improving system stability and decreasing the quantity of operating mode variations. A related hybrid microgrid configuration was introduced in [17]. Ref. [18] suggests appropriate day-ahead scheduling concerning the inclusion of hybrid microgrids in frequency regulation-based requirements. To service a frequency regulation market, all Distributed Generation (DG) comprising the microgrid is analysed for the balance between energy production and associated services. The authors in [19] suggest a technique for optimal power transmission and management in AC/DC hybrid microgrids. The penetration ratio specific to microgrids is a crucial indicator of the appropriate location of a microgrid in a power distribution setup. This study identifies the optimal location of the microgrid, considering two distribution systems. For these systems, the line losses and voltage characteristics are studied. Even though microgrids are taken into account on a minor scale, their technical intricacy of modelling and simulation is greater as against the traditional energy system. Hence, models facilitating dynamic analyses are crucial to ensure the stability of future microgrids.

In contrast, there are three topologies specific to decoupled AC systems: a totally isolated two-stage setup, a setup comprising two partially-isolated stages, and a setup comprising three partially isolated stage. The environment and application for which the AC/DC hybrid microgrid shall be used to determine the optimal configuration [20]. The critical aspect of an interconnected setup is the direct connection of an AC microgrid with the utility grid using an AC converter. The microgrid connects with the utility grid with the transformer being set up at the point of connection, thereby creating galvanic isolation for microgrid and also decreasing voltage specific to low voltage AC grid. Hybrid microgrids connected with the primary grid can regulate bidirectional power transfer (production/consumption) by employing AC/DC VSC for battery energy storage setups. It is necessary to highlight that hybrid microgrids can be scaled with ease. Moreover, the implementation of such microgrids may be performed at several levels using different configurations. These microgrids can be integrated with a Low-Voltage (LV) residential-scale grid or a Medium Voltage (MV) distribution-level grid [21].

The literature has several references for Grid-Connected Inverters (GCI) using PR controllers. Few studies specify the process of designing the PR controller [22-24]. All specified research is appropriate and highlights PR efficacy. Nevertheless, most research focuses on the PR controller being used in continuous-time. In contrast, a major proportion of the GCI applications require a digital setup. In such cases, the task of using the PR controller digitally is something the reader should ascertain.

The main unique contributions of the approach recommended in this paper can be summed up as shown below:

1. This work aims to formulate a model that can assess the behaviour of distributed energy resources in 14-node IEEE systems that stem from the change in the opening protocol of the disconnector, which establishes a power generating island. The stability analysis it exposes makes it possible to determine the performance of a radial distribution power system given various disturbances. Results have relevance in the operation and planning phases of a distributed generation system. 
2. As a renewable energy interface, numerous control technologies can be used to operate controlled inverters or rectifiers. In this study, some converters operated in an open-loop control strategy while others operated in a closed-loop control strategy. Furthermore, pulse width modulation techniques at varying carrier frequencies were utilised by these rectifiers or inverters.

3. The main contribution of this paper the proposed method not only focused on the transient response but also improve the steady-state response which smooth the voltage, furthermore all inverters are effectively involved to increase capacity of the microgrid for better power management.

4. The hybrid microgrid was equipped with nonlinear and linear loads, typical energy storage systems, and balanced and unbalanced loads. Moreover, this paper thoroughly describes the model with all the data needed to tackle the abovementioned studies.

5. This paper offers a design process for the digital PR current controller implemented to a GCI. The procedure describes a step-by-step method for calculating the resonant and proportional gains, as well the resonant path's coefficients. Its main contribution is helping facilitate and providing support to researchers who are tasked with designing GCI that incorporates present control strategies in a digital environment. The paper will also present an analysis of the frequency domain of a digital PR controller. This analysis utilised the fictitious w-domain. The case-study demonstrated the efficacy of GCI that uses a digital PR current controller, which was designed with the help of the proposed procedure. The paper also demonstrates how the proposed procedure has validity for a number of resonant path PR controllers.

\section{Proposed System Description}

The studied hybrid microgrid is composed of a photovoltaic array, together with batteries, and AC loads. These systems form a hybrid microgrid interconnected to a low voltage distribution. Figure 1 illustrates the configuration of a hybrid power system for the distribution microgrid.

The IEEE 14 bus feeder is the basis of the test platform for the hybrid microgrid developed in this report. The test feeder has been significantly modified to include diesel generators, detailed domestic dynamic multi-home models, battery storage systems and photovoltaic. The network diagram of the proposed distribution system is shown in Figure 1. The location of the photovoltaic generator, batteries and diesel generator used in this article is also indicated. It consists of a substation, 14 lines, 14 buses or nodes and 9 houses. The house consists of a combination of constant current, continuous impedance and constant loads of power. The network proposed incorporates a microgrid with an electric transmission system of $69 \mathrm{kV}$. There were two voltage output stages. The primary voltage was $13.8 \mathrm{kV}$ and the secondary voltage was $0.22 \mathrm{kV}$. In the proposed system, three sub-microgrids have been given: $\mathrm{AC}$ microgrid 1 is an AC microgrid 2-related area of $0.22 \mathrm{kV}$ through lines 4, 5, 6 . In addition, $\mathrm{AC}$ microgrid 1 provides electricity to 4 houses and is powered by a diesel generator. AC microgrid 2 is another area with battery power storage 2 and photovoltaic 2 feature. The two AC microgrids run at $50 \mathrm{~Hz}$. Ultimately, the third zone is the photovoltaic $1 \mathrm{DC}$ microgrid and a battery power storage system 1 . The battery power storage system 1 is connected by a two-way buck-boost converter, while photovoltaic 2 and DC connections are connected by a boost converter. The DC Bus and the AC microgrid 2 are connected by two parallel bidirectional transformers, which can be used as inverters or rectifiers for two transformers to swap reactive and active power. Finally, this hybrid $\mathrm{AC} / \mathrm{DC}$ system also has a load equivalent grid network and diesel generators. 


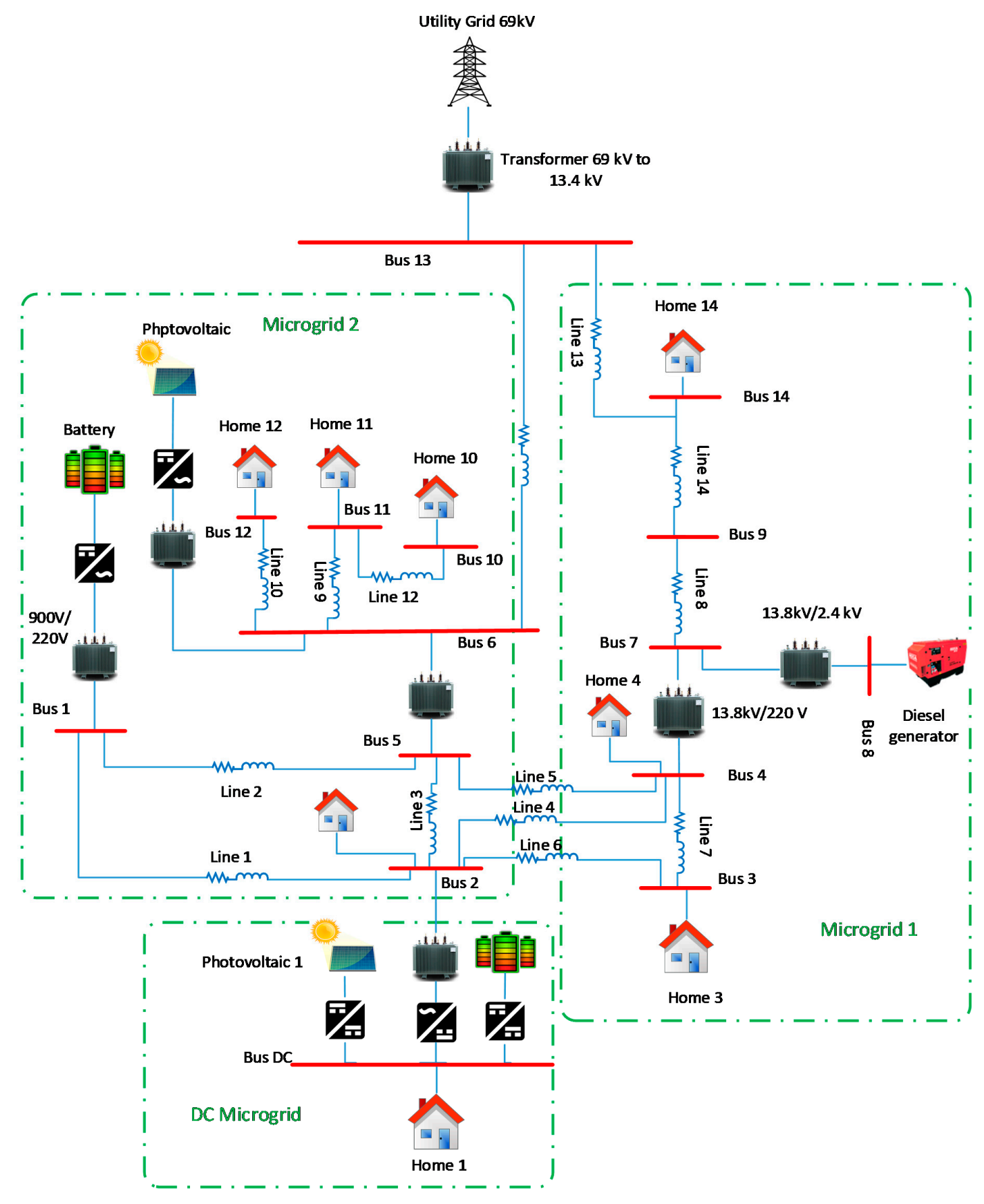

Figure 1. The proposed hybrid microgrids system structure.

\section{Distributed Hybrid Energy Generation System}

\subsection{Photovoltaic Modelling}

Figure 2 illustrates the equivalent circuit of the photovoltaic [25]. Figure 3 shows the voltage and current curve [26-28].

$$
I=I_{p h, \text { cell }}-\underbrace{I_{o, \text { cell }}\left[\exp \left(\left(q\left(V+I R_{-}(s, \text { cell })\right) / a k T\right)-1\right]\right.}_{I_{d, \text { cell }}}-\frac{V+I R_{s, \text { cell }}}{R_{p, \text { cell }}}
$$


where $k$ is constant of Boltzmann's $1.38 \times 10^{-23} \mathrm{~J} / \mathrm{K} q$ is the charge of the electron $\left(1.602 \times 10^{-19} \mathrm{C}\right), I_{0, \text { cell }}$ is the saturation current or reversed leakage of the photovoltaic, $I_{p h \text {, cell }}$ is the photocurrent (A) of the photovoltaic, $R_{s, \text { cell }}$, is the series resistance of photovoltaic, $R_{p, c e l l}$ is parallel resistance of photovoltaic.

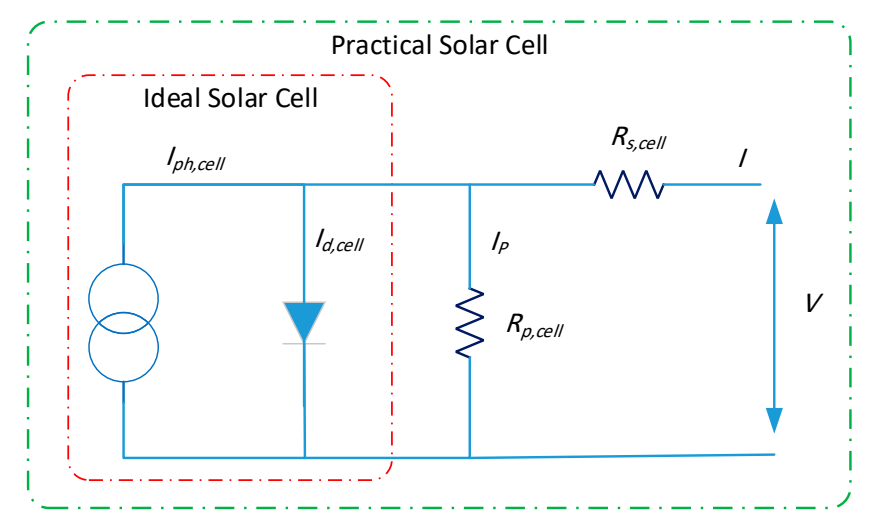

Figure 2. Photovoltaic equivalent circuit.
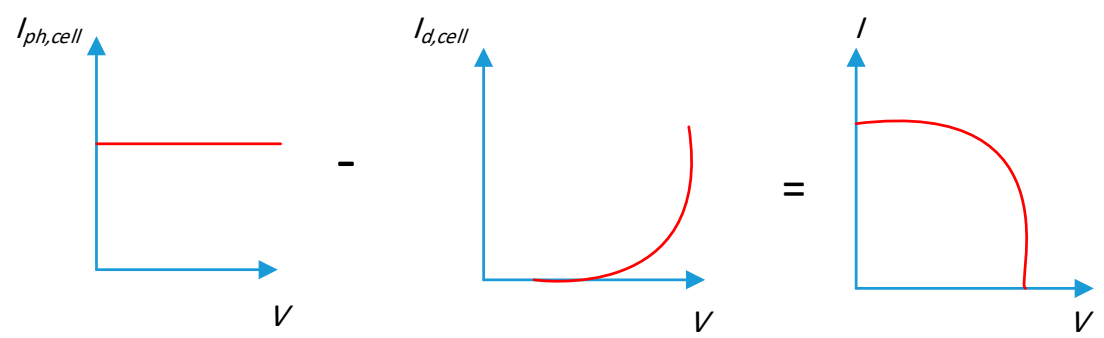

Figure 3. Photovoltaic voltage and current curve.

A photovoltaic module is previously stated to consist of photovoltaic cells joint in parallel and in series. The basic mathematical equation is therefore obtained based on Equation (1) and the description for the voltage and current characteristics of photovoltaic module will be as follows:

$$
I=I_{p h, \text { cell }}-I_{0}\left[\exp \left(\frac{V+I R_{S}}{a V t}\right)-1\right]-\frac{V+I R_{S}}{R_{p}}
$$

where: $I_{p h \text {, cell }}$ is the photocurrent (A) of the photovoltaic, $I_{o}$ is photovoltaic reverse leakage current, $V_{t}$ is photovoltaic thermal voltage, $R_{p}$ is parallel resistance, $R_{S}$ is photovoltaic series resistance, Equation (2) generates the current and voltage curve as illustrated in Figure 4.

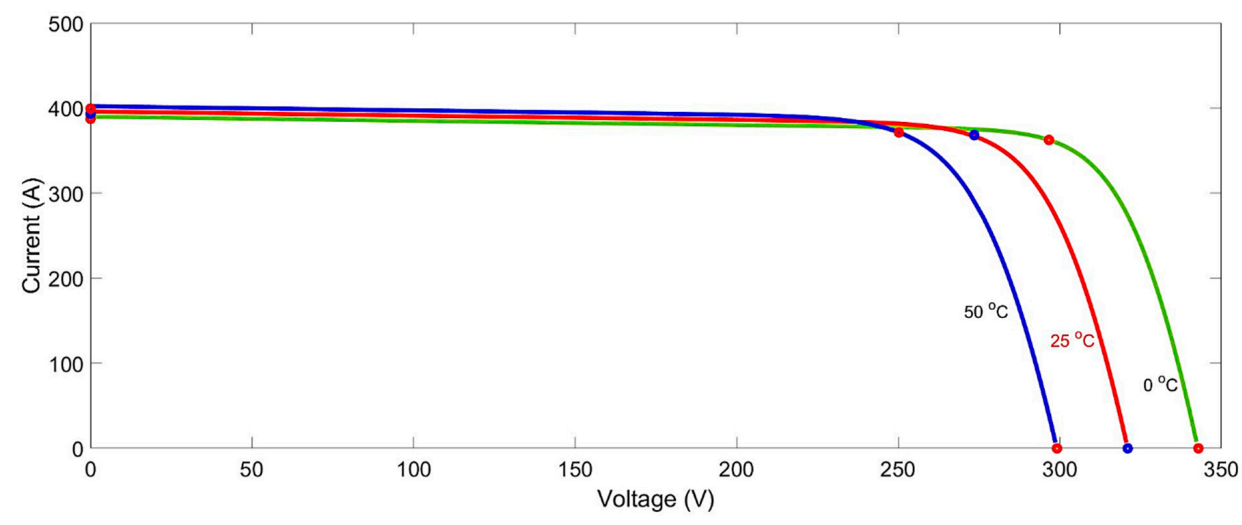

Figure 4. The photovoltaic voltage and current curves. 
This corresponds to Equation [29]:

$$
\begin{gathered}
I_{p h}=\frac{G}{G_{n}}\left(I_{p h ; n}+K_{i} \Delta T\right) \\
V_{o c}=V_{o c ; n}+K_{v} \Delta T \\
I_{o}=\frac{I_{s c ; n}+K_{i} \Delta T}{\exp \left(\frac{V_{o c ; n}+K_{v} \Delta T}{a V_{t}}\right)-1}
\end{gathered}
$$

where $I_{s c ; n}$ is short circuit current under the nominal conditions, $\Delta T$ refers to the difference between the PV cell's actual temperature $(T)$ and a temperature $\left(T_{n}\right)$ measured in ${ }^{\circ} \mathrm{C}, G_{n}$ is an irradiance $\left(1000 \mathrm{w} / \mathrm{m}^{2}\right), I_{p h ; n}$ represents the photocurrent when it is under the nominal condition (typically a $1000 \mathrm{w} / \mathrm{m}^{2}$ irradiance and $25^{\circ} \mathrm{C}$ temperature), $G$ is a measured solar irradiance in w/m $/ \mathrm{m}^{2} K_{i}$ is the temperature coefficient [30]. In this paper, the electrical parameters of the SPR-305E-WHT-D solar is extracted and used to simulate this modular model. These parameters are listed in Table 1.

Table 1. Photovoltaic parameters.

\begin{tabular}{cc}
\hline Parameters & Values \\
\hline Series connected modules & 7 \\
Parallel string & 1 \\
Maximum current $I_{m p}$ & $5.58(\mathrm{~A})$ \\
Maximum voltage $\left(V_{m p}\right)$ & $54.7(\mathrm{~V})$ \\
Short-circuit current $\left(I_{s c}\right)$ & $5.96(\mathrm{~A})$ \\
Voltage of open circuit $\left(V_{o c}\right)$ & $6.42(\mathrm{~V})$ \\
Temperature coefficient of $\left(I_{s c}\right)$ & $0.061745\left(\% /{ }^{\circ} \mathrm{C}\right)$ \\
Temperature coefficient of $\left(V_{o c}\right)$ & $-0.27269\left(\% /{ }^{\circ} \mathrm{C}\right)$ \\
Shunt resistance $\left(R_{s h}\right)$ & $269.5934 \Omega$ \\
Series resistance $\left(R_{s}\right)$ & $0.37152 \Omega$ \\
Diode saturation curent $I_{o}$ & $6.3 \times 10^{-1}(\mathrm{~A})$ \\
Number of cells & 96 \\
\hline
\end{tabular}

\subsection{Batteries}

Battery storage systems are used to store additional energy produced by systems for the production of renewable energy. However, if the renewable energy system does not produce sufficient electricity, battery discharge should meet the demand for the load. Type battery is as follows [31]:

$$
\begin{gathered}
S O C_{b a t}=100\left[1-\left(\frac{1}{Q_{b a t}} \times \int_{0}^{t} i_{b a t}(t) d t\right)\right] \\
B_{A H}=\frac{1}{3600} \int_{0}^{t} i_{b a t}(t) d t
\end{gathered}
$$

where $i_{b a t}$ represents the current of the battery, $Q_{b a t}$ refers to the maximum battery capacity (Ah), $S O C_{b a t}$ refer to the state of charge of the battery (\%).

\subsection{Loads}

The loads are made up of residential loads. The design of residential loads is based on the resort island's daily non-seasonal consumption. Furthermore, simulation of the residential loads are performed based on the actual difference in the specified resort island's specific loads profile. The data of microgrid are listed in Table 2. 
Table 2. Microgrid load data.

\begin{tabular}{ccccc}
\hline Loads Name & Min-Loads (kVA) & Max-Loads (KVA) & Load Type & Power Factor \\
\hline Home2 & 13 & 39 & AC & 0.89 \\
Home3 & 10 & 29 & AC & 0.9 \\
Home4 & 14 & 49 & AC & 0.89 \\
Home9 & 100 & 319 & AC & 0.99 \\
Home10 & 239 & 799 & AC & 0.9 \\
Home11 & 119 & 399 & AC & 0.92 \\
Home12 & 239 & 799 & AC & 0.93 \\
Home14 & 479 & 1599 & AC & 0.85 \\
Home1 & 0.7 & 3 & DC & 0.99 \\
\hline
\end{tabular}

\subsection{Diesel Generator}

Diesel generators provide balance in demand for load and the electricity produced in the microgrid. This model consists of a diesel engine, an anticipation system, a control system and a synchronous computer. The governor system and diesel engine models are coupled with two inputs, real (p.u.) speed and the required speed in one unit. The mass production refers to the mechanical power of the diesel engine. The console has similarities to following transfer function [32]:

$$
H_{c}=\frac{k\left(1+T_{3} S\right)}{1+T_{1} S+T_{1} T_{2} S}
$$

where $k$ represents proportional gain, $T_{1}, T_{2}$ and $T_{3}$ refer to time constants of the regulator (seconds). Below is the actuator transfer function:

$$
H_{a}=\frac{1+T_{4} S}{\left[s\left(1+T_{5} S\right)\left(1+T_{6} S\right)\right]}
$$

Alternatively, the design of diesel engine generators has a time delay that delays the operator's torque output for a specified period. The transfer function below describes the excitation system of the machine [32]:

$$
\frac{V_{f d}}{V_{r o}}=\frac{1}{K_{s}+S T_{e}}
$$

where $V_{f d}$ represents the exciter voltage, $V_{r o}$ represents the output of the regulator, $K_{s}$ refers to the gain and $T_{e}$ represents the time constant.

\subsection{The Lines Data}

In AC and low-voltage distribution levels standard microgrid distribution lines are common. For the main $13.8 \mathrm{kV}$ network, the unit resistance of the line is $0.339 \mathrm{ohm}$ per kilometer, the unit reactance of line is $0.1168 \mathrm{ohm}$ per kilometer and its impedance is $0.41 \mathrm{ohm} / \mathrm{kilometer}$. More details are provided in Table 3 [33].

Table 3. Microgrid line data.

\begin{tabular}{cccc}
\hline Lines & Resistors $(\mathbf{o h m})$ & Inductance & Distances $\mathbf{( k m )}$ \\
\hline 1 & 0.029 & 0.016 & 0.15 \\
2 & 0.039 & 0.021 & 0.2 \\
3 & 0.029 & 0.016 & 0.15 \\
4 & 0.079 & 0.043 & 0.4 \\
5 & 0.079 & 0.043 & 0.4 \\
6 & 0.079 & 0.043 & 0.4 \\
7 & 0.019 & 0.01 & 0.1 \\
8 & 0.78 & 0.23 & 2 \\
9 & 2.36 & 0.70 & 6 \\
10 & 2.36 & 0.70 & 6 \\
11 & 1.18 & 0.35 & 3 \\
12 & 2.36 & 0.7 & 6 \\
13 & 1.18 & 0.35 & 3 \\
14 & 0.78 & 0.23 & 2 \\
\hline
\end{tabular}




\section{Controller of the Inverters}

Figure 5 shows the control method of the inverter. The inverter output current is sensed and the grid voltage is transmitted to the control board.

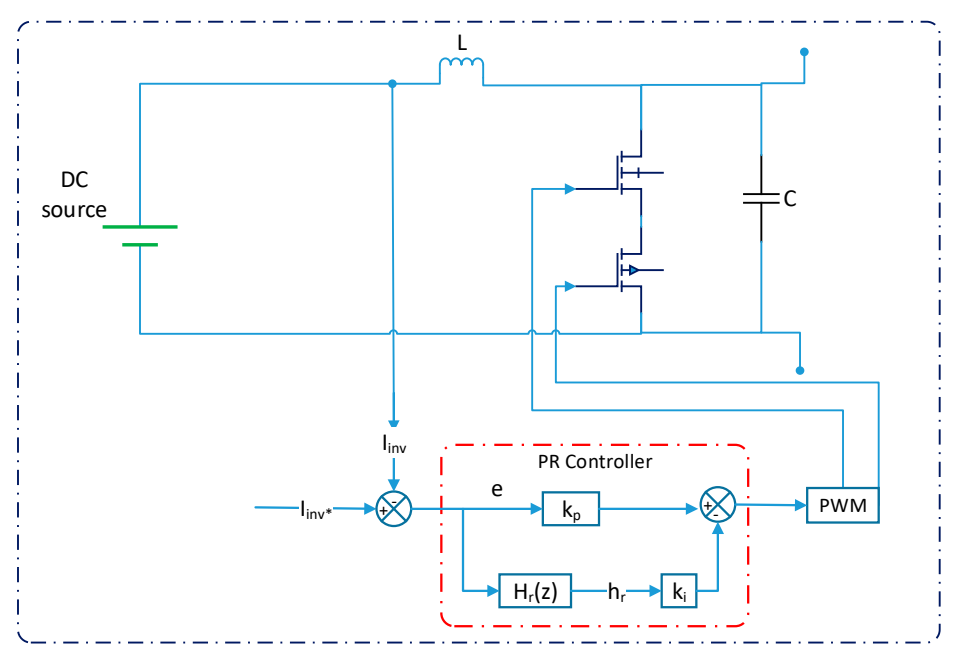

Figure 5. Proposed control block diagram.

The inverter output current is compared with the reference voltage, generating an error signal that passes through the optical proportional resonant controller. The Pulse Width Modulation (PWM) method is used for the operation of a proportional resonant output signal in the inverter. The modulator's amplitude carrier is equal to one. A grid tension synchronized sinusoidal signal is the reference, which is why voltage sensing and transmission is performed in the diagram. A phase-locked loop is completed to ensure synchronization, although not shown in this figure. The current control loop time constant is slightly longer compared to the PWM time delay. The delay caused by the PWM can therefore be overlooked without affecting the current controller design.

\section{Controller of Proportional Resonant}

Figure 5 shows the digital PR controller going from a proportional gain $\left(\ell_{p}\right)$ and into a resonant direction. As given by Equation (11) and described by the z-domain transfer $\mathscr{H}_{r}(\approx)$ function, the resonant path is consistent with the resonant filter and the resonant gain $\left(k_{i}\right)$.

$$
\mathscr{H}_{\mu}(*)=\frac{\hbar^{-2} b_{2}+\hbar^{-1} b_{1}+b_{0}}{\hbar^{-2} a_{2}+\hbar^{-1} a_{1}+a_{0}}
$$

where: $b_{0}, b_{1}$ and $b_{2}$ are a constant, and $a_{0}, a_{1}, a_{2}$ are real constants.

The resonant filter is often referred to as Notch Filter. The word resonant filter is used in this article. The digital PR controller architecture thus results in the values $k_{2}, k_{i}, a_{0}, a_{1}, a_{2}, b_{0}, b_{1}$, and $b_{2}$. This section describes a design procedure for half-bridge inverters in Figure 1. However, this process is also applicable to the three-phase inverter and the full-bridge inverters. For the three-phase inverter, designed PR controller can be repeated in the other phases. Knowing the system parameters as shown in Table 4 [34]. 
Table 4. Parameter of the system [34].

\begin{tabular}{ccc}
\hline Parameters & Units & Symbols \\
\hline Inductance of Inverters & $\mathrm{H}$ & $L_{i n v}$ \\
resistance of Inverter & $\Omega$ & $R_{i n v}$ \\
DC link Voltage & $\mathrm{V}$ & $V_{d c}$ \\
Switch frequency & $\mathrm{Hz}$ & $f_{s w}$ \\
Current sensor gain & $\mathrm{A}$ & $H_{i}$ \\
Inverter power & $\mathrm{W}$ & $P_{i n v}$ \\
Sampling frequency & $\mathrm{Hz}$ & $f_{a}$ \\
Sampling angle frequency & $\mathrm{Rad} / \mathrm{second}$ & $\omega_{a}=2 \pi f_{a}$ \\
Sampling period & $\mathrm{s}$ & $T_{a}=1 / f_{a}$ \\
Grid peak voltage & $\mathrm{V}$ & $V_{p}$ \\
Frequency of grid & $\mathrm{Hz}$ & $f_{g}$ \\
Angle frequency of grid & $\mathrm{Rad} / \mathrm{s}$ & $\omega_{g}=2 \pi f_{g}$ \\
\hline
\end{tabular}

PR controller resonant $\left(b_{i}\right)$ and proportional $\left(b_{p}\right)$ gains are calculated in Equations (12) and (13) [35].

$$
\begin{gathered}
b_{i}=\frac{1}{h_{i}} \times \frac{\left((1+2 \text { mathscru })^{2}-1\right) \times \mathscr{L} \times w_{\mu}^{2}}{\mathscr{V}_{d c}} \\
\hbar_{R}=\frac{2}{h_{i}} \times \frac{-\mathscr{R}+\sqrt{(1+2 u)} \times \mathscr{L} \times w_{\mu} \times(1+2 \text { mathscru })}{\mathscr{V}_{d c}}
\end{gathered}
$$

The third stage involves the calculation of the $a_{0}, a_{1}, a_{2}, b_{0}, b_{1}$ and $b_{2}$ coefficients to be used for the z-domain transfer function. To obtain these coefficients, the Z-transform could be applied to the s-domain analogue resonant filter transfer functions below:

$$
\mathscr{H}_{\mu}(s)=\frac{s \times \mathscr{B}_{\mu} \times k_{\mu}}{w_{\mu}^{2}+2 \mathscr{B}_{\mu} s+s^{2}}
$$

When the Z-transform is applied in Equation (14), the optical resonant filter is given by the Backward-Euler approximation.

$$
\mathscr{H}_{\mu}(\varkappa)=\frac{\hbar^{-2} b_{2}+\hbar^{-1} b_{1}+b_{0}}{\hbar^{-2} a_{2}+\hbar^{-1} a_{1}+a_{0}}
$$

The resonant filter coefficients are thus indicated by the following expressions:

$$
\begin{gathered}
b_{0}=\mathscr{T}_{a} \times \mathscr{B}_{\mu} \times \hbar_{\mu} \\
b_{1}=\mathscr{T}_{a} \times\left(\cos \left(\mathscr{T}_{a} \times \sqrt{-0.2 \mathscr{B}_{\mu}+w_{\mu}^{2}}\right) \times\left(-\mathscr{B}_{\mu} \hbar_{\mu} e^{-0.5 \mathscr{T}_{a} \mathscr{B}_{\mu}}\right)-\mathscr{C}\right)
\end{gathered}
$$

where:

$$
\begin{aligned}
& b_{2}=0 \\
& a_{2}=e^{\mathscr{T}_{a} \mathscr{B}_{r}}, b_{2}=0 a_{2}=e^{\mathscr{T}_{a} \mathscr{B}_{r}}, b_{2}=0 \\
& a_{1}=\cos \left(\mathscr{T}_{a} \times \sqrt{-0.2 \mathscr{B}_{\mu}+w_{\mu}^{2}}\right) \times\left(-\mathscr{B}_{\mu} k_{\mu} e^{-0.5 \mathscr{T}_{a} \mathscr{B}_{\mu}}\right) \\
& a_{0}=1 \\
& \mathscr{C}=\sin \left(\mathscr{T}_{a} \times \sqrt{-0.2 \mathscr{B}_{\mu}+w_{\mu}^{2}}\right) \times e^{-0.5 \mathscr{T}_{a} \mathscr{B}_{\mu}} \times \frac{-0.5 \mathscr{T}_{a} \mathscr{B}_{\mu}}{\sqrt{-0.2 \mathscr{B}_{\mu}+w_{\mu}^{2}}}
\end{aligned}
$$


Note that the a0 is deliberately defined as 1 to allows $z$-domain transmission function in Equation (11) to be written as a differential equation by

$$
y(n)=-a_{1} y(n-1)-a_{2} y(n-2)+b_{0} \times \mathscr{u}(n)+b_{1} \times \mathscr{U}(n-1)+b_{2} \times \mathscr{U}(n-2)
$$

where $y(n)$ represents the resonant filter output and $\mathscr{U}(n)$ represents the resonant filter input. This step can be considered as one of the main contributions of this work. This makes it possible for the designer to compute for resonant filter coefficients when only the desired filter frequency response is defined in the s-domain. Then, Equations (16) to (22) provide digital implementation coefficients.

\section{Case-Study}

The case study is performed to design a digital PR controller as illustrated in Figure 1. Table 5 displays the parameters. The resonant gain for the analogue filter was chosen as optical PR sensor's resonant gain was separately determined Equation (13). Table 6 present parameter of designed digital PR controllers. To be more precise, all values obtained must be at least 12 decimal points [34].

Table 5. Case study parameter value.

\begin{tabular}{ccc}
\hline Parameters & Units & Symbols \\
\hline Inductance of Inverter & $10 \mathrm{mH}$ & $L_{i n v}$ \\
Resistance of Inverter & $0.5 \mathrm{~m} \Omega$ & $R_{i n v}$ \\
Voltage of DC link & $450 \mathrm{~V}$ & $V_{d c}$ \\
Current sensor gain & $0.1 \mathrm{~A}$ & $H_{i}$ \\
Power of inverter & $1500 \mathrm{~W}$ & $P_{i n v}$ \\
Sampling angle frequency & $1.88 \times 10^{5} \mathrm{Rad} / \mathrm{s}$ & $\omega_{a}=2 \pi f_{a}$ \\
Sampling period & $34 \mu \mathrm{s}$ & $T_{a}=1 / f_{a}$ \\
Grid Peak voltage & $180 \mathrm{~V}$ & $V_{p}$ \\
Angular frequency of grid & $377 \mathrm{Rad} / \mathrm{s}$ & $\omega_{g}=2 \pi f_{g}$ \\
Inductance of grid & $100 \mu \mathrm{H}$ & $L_{g}$ \\
Resistor of grid & $0.1 \mathrm{~m} \Omega$ & $R_{g}$ \\
Resonant angle frequency & $377 \mathrm{Rad} / \mathrm{s}$ & $\omega_{r}=2 \pi f_{r}$ \\
Resonant bandwidth & $1.5 \mathrm{~Hz}$ & $B_{s}$ \\
Bandwidth of Resonant angular & $10 \mathrm{rad} / \mathrm{s}$ & $B_{s}=2 \pi B_{s}$ \\
Resonant gains & $k_{r}$ & 1 \\
\hline
\end{tabular}

Table 6. Designed digital Proportional-Resonant (PR) controller [34].

\begin{tabular}{ccc}
\hline Parameters & Variables & Values \\
\hline Proportional gain & $k_{p}$ & 0.827 \\
Resonant gain & $k_{i}$ & 234.02 \\
B0 coefficient & $b_{0}$ & $3.14 \times 10^{-4}$ \\
B1 coefficient & $b_{1}$ & $-3.14 \times 10^{-4}$ \\
B2 coefficient & $b_{2}$ & 0 \\
A0 coefficient & $a_{0}$ & 1 \\
A1 coefficient & $a_{1}$ & -1.99 \\
A2 coefficient & $a_{2}$ & 0.99 \\
\hline
\end{tabular}

\section{Proposed System Analysis}

Two analytical schemes are established to compute metrics for describing the primary cases concerning future studies focusing on optimisation and compensation. Figure 6 depicts the characteristics of daily demand for the suggested hybrid microgrid system. The curve is obtained by computing total hourly demand specific to every load defined by the model, which includes the critical load components, namely commercial and industrial. Load modelling was based on fixed impedance; therefore, the nominal power and actual power used differ slightly because of the voltage drop 
created in the system. As illustrated in Figure 6, the system's minimum demand is only $30 \%$ of the maximum demand. Active and reactive power demand in the system is assumed to have a similar relationship. The minimum demand situation must be used to ascertain the capacity and placement of the compensation mechanism. Interacting compensating components may cause an overvoltage scenario in the system. Referring to Figure 6, it can be observed that there is maximum demand at 11:00, which is also the time at which solar radiation, and, therefore, solar power production is also maximised. The increased power demand witnessed at this time is caused by the combination of industrial and domestic loads.

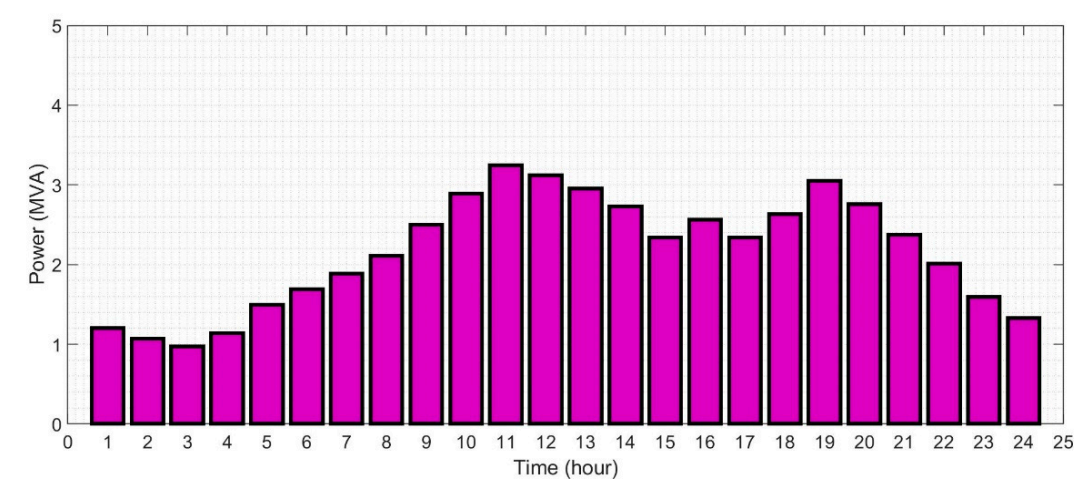

Figure 6. The curve of demand for one day.

\section{Voltage Analysis}

Figure 7 depicts the voltage profile determined for analysing the maximum load energy scenario, while Figure 8 depicts the voltage profile for minimum load capacity. The system operates under single-phase loading leading to unbalanced loads, thereby warranting a voltage profile analysis. In both situations, the voltage profile adheres to the appropriate operating standards. Nevertheless, as highlighted in Figure 7, when demand is at its maximum level, low voltage grid (220 V) buses 2 and 3 witness a noteworthy drop in voltage. Voltage profile quality is specified using indicators depicted in Figures 7 and 8. Equations (24) and (25) specify the calculation for average voltage deviation for the system.

$$
\text { Voltage Average Deviation }=\frac{1}{n} \times \sum_{n=1}^{n}\left|\mathscr{V}_{d i}-\mathscr{V}_{i}\right|
$$

where: $\mathscr{V}_{d i}$ is the desired voltage, and $\mathscr{V}_{i}$ is the bus voltage, and $\mathrm{n}$ is the buses number.

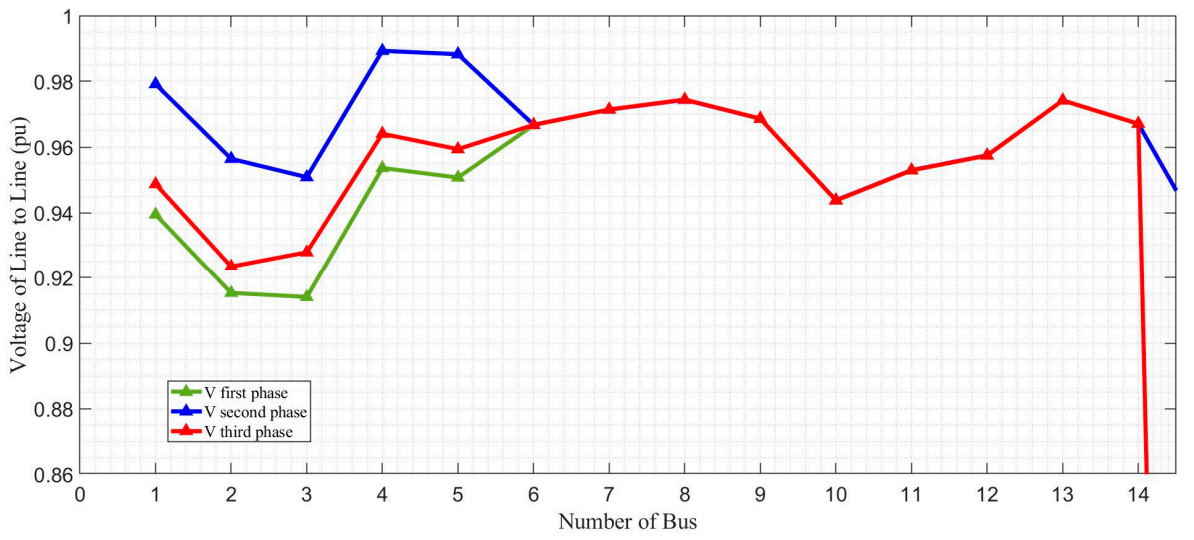

Figure 7. Maximum demand voltage. 


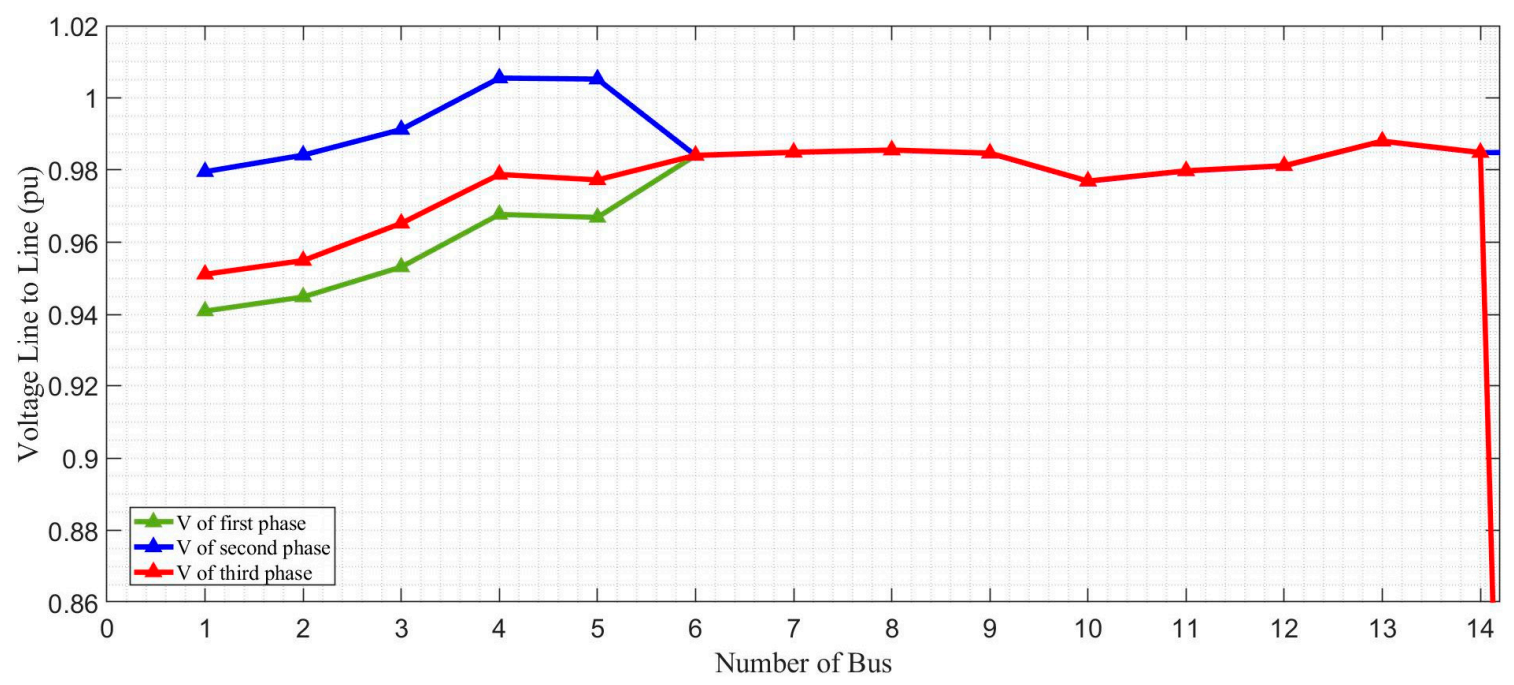

Figure 8. Minimum demand voltage.

The maximum voltage deviation magnitude is represented by [33]:

$$
\text { Maximum Voltage Deviation }=\max _{1 \leq i \leq n}\left[\left|\mathscr{V}_{d i}-\mathscr{V}_{i}\right|\right]
$$

Using Figure 7, it can be seen that, under a peak demand situation, the maximum average voltage deviation for the system is up to 0.048 per unit. Nevertheless, this system is determined to have a maximum voltage deviation of 0.072 on bus 3 (first, second, and third stage values are 0.087, 0.05 , and 0.08 , respectively). Figure 8 depicts that, under a minimum load situation, the voltage profile for all buses is positive. The computation of the average of maximum deviations and system voltage deviations is quite low, thereby highlighting that the system is operating under appropriate conditions. The analysis and computation for this scenario were performed concerning the reactive power compensation scheme to address maximum demand situation that could potentially affect minimum demand setting with respect to its voltage profile.

In the case study, the fictitious w-domain was used to numerically check the precision and frequency response of the system PR controller with a fictional w-plane. W-domain is a technique that allows structures to be evaluated in a z-domain near the s-domain by frequency charts. All advantages in the frequency domain are regarded as true for the mapping of the $\mathrm{z}$ plane into the $\mathrm{w}$ plane, except for high frequency. The w-transformation is given by the z-plane to the w-plane transformation.

$$
\begin{gathered}
z=\frac{\frac{w \times \mathscr{T}_{a}}{2}+1}{-\frac{w \times \mathscr{T}_{a}}{2}+1} \\
v=\frac{2}{\mathscr{T}_{a}} \tan \frac{w \times \mathscr{T}_{a}}{2}
\end{gathered}
$$

The PR controller's resonant filter, described by $\mathscr{H}_{\mu}(\varkappa)$, is first analysed. The built resonant filter is therefore mapped to the w-plane.

$$
\begin{gathered}
h_{\mu}(w)=\left.h_{\mu}(\varkappa)\right|_{z=\frac{w \times \mathscr{T}_{a}}{2}+1} \\
-\frac{w \times \mathscr{T}_{a}}{2}+1 \\
\text { magnitude } \left.(v)=20 \log \mid h_{\mu}(w)\right) \mid \\
\text { Phase }(v)=\operatorname{argument}\left|h_{\mu}(w)\right|
\end{gathered}
$$


Figure 9 shows the magnitude response of the design resonant filter in $\mathrm{w}$-domain. Note that in the third phase of the design process, the resonant filter does not include the resonant gain measured. Figure 10 shows the magnitude response phase response of the designed PR controller. Figure 11 illustrate the output current of inverters.

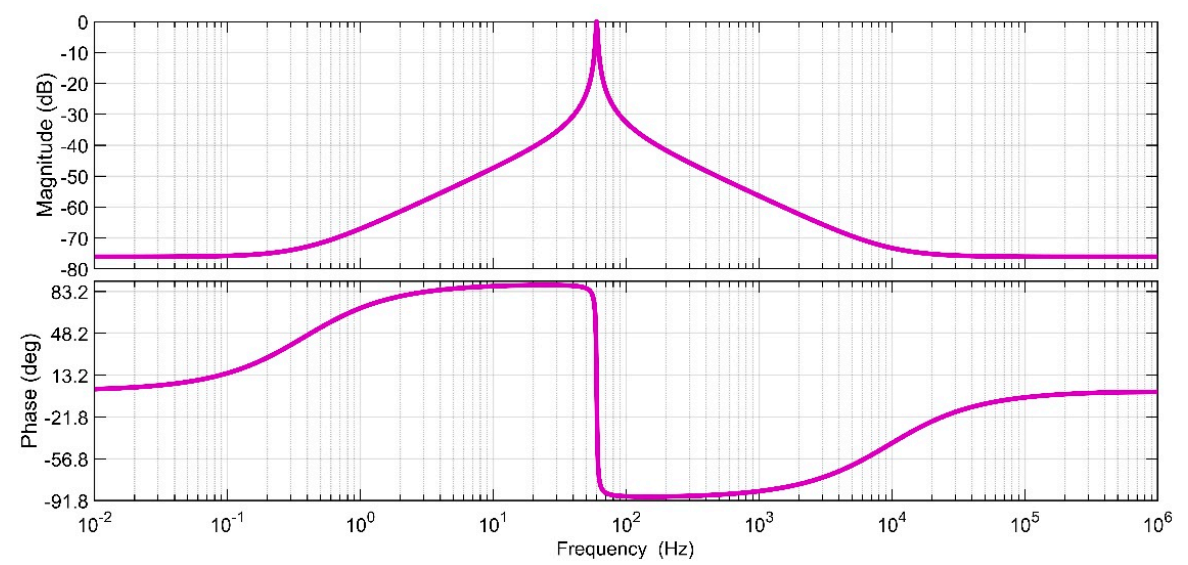

Figure 9. Phase and magnitude response of the resonant filter.

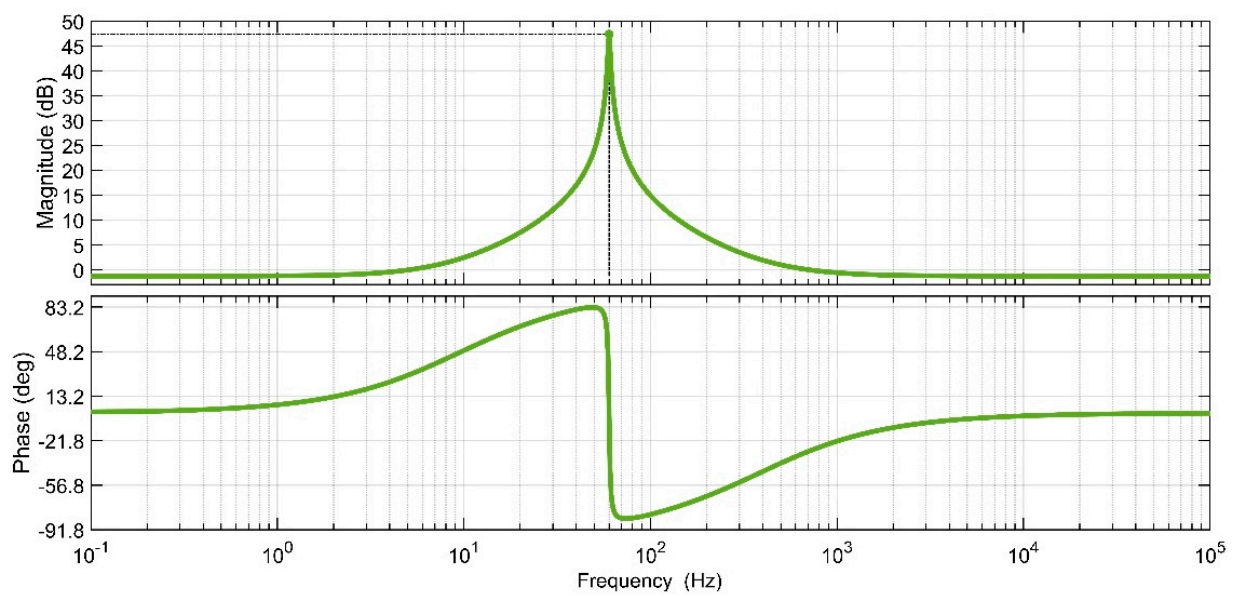

Figure 10. PR controller magnitude response and phase response controller.

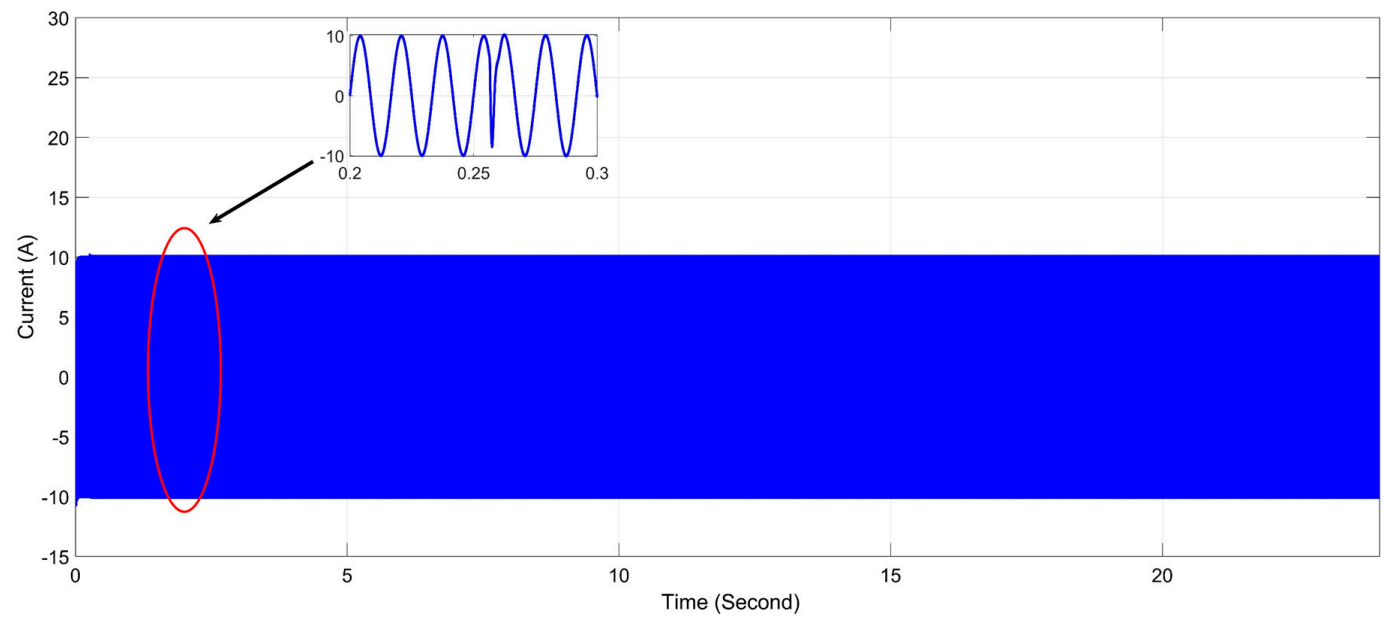

Figure 11. The output current of inverters. 


\section{Power Flow Result}

Figure 1 shows the hybrid microgrid system, in which all vector angle values are calculated with a phase-locked notch filter adaptive to a loop. Phase lock loop has an auxiliary circuit which gets the phase angle at one stage from the instantaneous voltage waveform. In addition, the angle of the phase current is obtained in the same phase from the instantaneous current wave. Then these two values are subtracted before $\theta$ for all buses is calculated.

At the basic frequency, the power block calculates the reactive power $\left(\mathscr{Q}_{i}\right)$ and active power $\left(\mathscr{P}_{i}\right)$ in the basic frequency. The output variables $\left(\mathscr{Q}_{i}\right)$ and $\left(\mathscr{P}_{i}\right)$ are then determined at every fundamental waveform time, as set out in Equations (31) and (32) [33]:

$$
\begin{aligned}
\mathscr{Q}_{i} & =\frac{1}{2} \times \sin \left(\theta_{i}\right) \times \mathscr{V}_{i} \times \mathscr{I}_{i} \\
\mathscr{P}_{i} & =\frac{1}{2} \times \cos \left(\theta_{i}\right) \times \mathscr{V}_{i} \times \mathscr{I}_{i}
\end{aligned}
$$

This section also demonstrates the proposed system's simulation result. Hybrid microgrids are responsible for stabilising the operations in stable condition under minimum and maximum demand scenario. Simulink furnished per phase calculations. However, the active and reactive power value presented in Tables 7 and 8 represent the sum of per phase power, or in other words, the sums for the three-phase active and reactive power. For any load bus, $\mathscr{P}_{1}$ and $\mathscr{Q}_{1}$ are presented, while $\mathscr{P}_{g}$ and $\mathscr{Q}_{q}$ are presented for any generator bus. Lastly, for any transfer bus, $\mathscr{P}_{\text {transfer }}$ and $\mathscr{Q}_{\text {transfer }}$ are given.

Table 7. Result of loads at minimum demand.

\begin{tabular}{ccccccccc}
\hline Bus & Angle (Degree) & $\mathbf{V}$ & $\mathscr{Q}_{\mathcal{g}}$ & $\mathscr{P}_{\mathcal{L}}$ & $\mathscr{Q}_{\mathbf{1}}$ & $\mathscr{R}_{\mathbf{1}}$ & $\mathscr{Q}_{\text {transfer }}$ & $\mathscr{R}_{\text {transfer }}$ \\
\hline 1 & -29 & 0.91 & 14 & 30 & & & & \\
2 & -29.9 & 0.94 & & & & & 6 & 15 \\
3 & -32 & 0.92 & & & 12 & 19 & 15 & 21 \\
4 & -30 & 0.93 & & & & & 26 & 49.9 \\
5 & -34 & 0.95 & & & & & 25 & 49 \\
6 & -32 & 0.94 & & & & & 90 & 480 \\
7 & -29 & 0.96 & & & & & & \\
8 & -65 & 0.96 & 50 & 140 & & & \\
9 & -29 & 0.93 & & & 0.70 & 109 & & \\
10 & -29 & 0.93 & & & 140 & 190 & & \\
11 & -29 & 0.99 & & & 70 & 89 & & \\
12 & -29 & 0.89 & & & 140 & 190 & & \\
13 & -29 & 0.93 & 70 & 89 & & & & \\
14 & -29 & 0.91 & & & 280 & 380 & 79 & 19 \\
\hline
\end{tabular}

Table 8. Result of loads at maximum demand.

\begin{tabular}{ccccccccc}
\hline Bus & Angle (Degree) & $\mathbf{V}$ & $\mathcal{Q}_{q}$ & $\mathscr{P}_{q}$ & $\mathcal{Q}_{\mathbf{1}}$ & $\mathscr{P}_{\mathbf{1}}$ & $\mathfrak{Q}_{\text {transfer }}$ & $\mathscr{R}_{\text {transfer }}$ \\
\hline 1 & -30.1 & 0.89 & 29.99 & 45 & & & & \\
2 & -29.5 & 0.90 & & & & & 5 & 39 \\
3 & -30.3 & 0.91 & & & 41 & 65 & 42 & 59 \\
4 & -32.4 & 0.92 & & & & & 90 & 125 \\
5 & -30.3 & 0.93 & & & & & 60 & 37 \\
6 & -32.2 & 0.94 & & & & & 1080 & 790 \\
7 & -31.1 & 0.90 & & & & & 350 & 560 \\
8 & -59.99 & 0.91 & 430 & 680 & & & & \\
9 & -29.9 & 0.93 & & & 37 & 330 & & \\
10 & -30.1 & 0.91 & & & 430 & 580 & & \\
11 & -29.99 & 0.92 & & & 220 & 280 & & \\
12 & -29.8 & 0.91 & & & 450 & 580 & & \\
13 & -29.7 & 0.89 & 1670 & 1820 & & & & \\
14 & -29.3 & 0.92 & & & 90 & 120 & 350 & 230 \\
\hline
\end{tabular}




\section{Active Power Balance per Bus}

Figures 12 and 13 highlights the power production and consumption characteristics (in kVA) for every system bus, including the power level $(\mathrm{kW})$ at the DC bus. A positive value on the graph indicates the power (load) drawn by the bus. Bus 14 has a negative power level; hence, there is a transfer to bus 14 from bus 9 acting as a source of power concerning the diesel generation. Tables 7 and 8 describe these situations along with the residual negative capacity for generation specific to the bus. Considering the maximum demand situation in Figure 12, there are six bus $(1,2,6,7,13$, and the DC bus) that generate power. Figure 13 depicts the balance of power in the system concerning the minimum demand situation. At maximum demand, the power level for every bus decreases. For this situation, the characteristics of distributed generation are specified, leaving diesel generator 8 connected to the bus. At the same time, the remaining inactive power contribution is made through bus 13 connected to the grid.

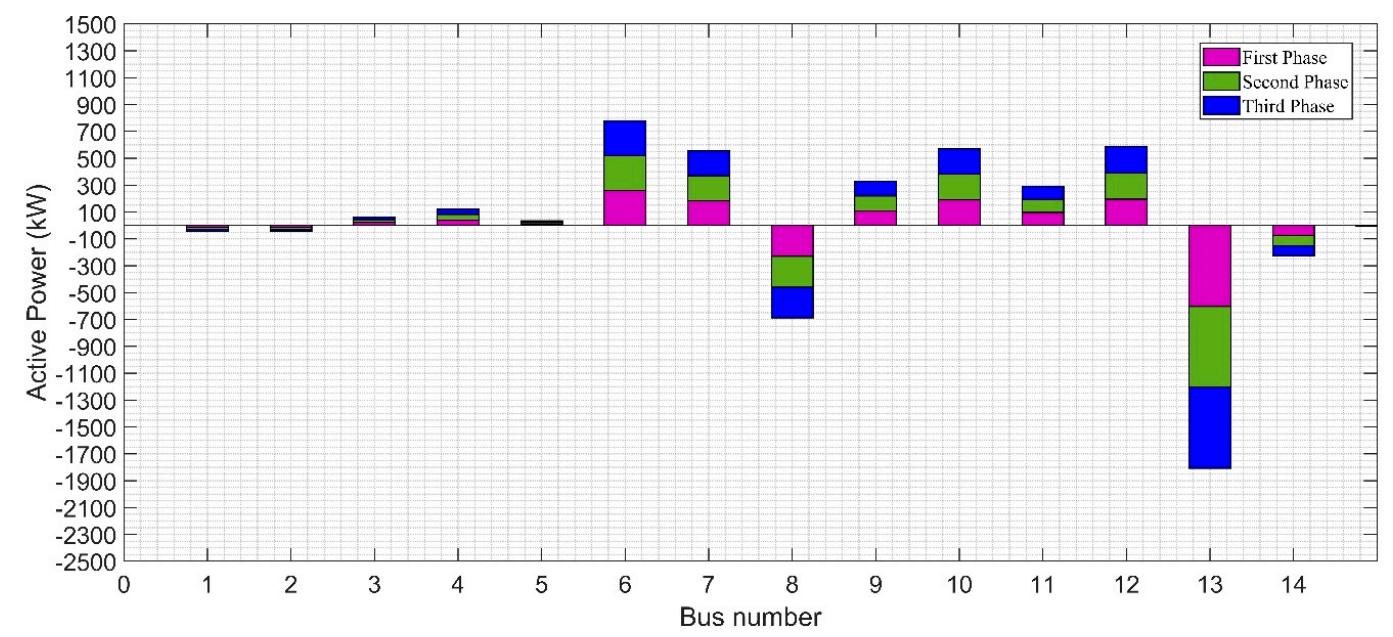

Figure 12. The maximum demand for power balance.

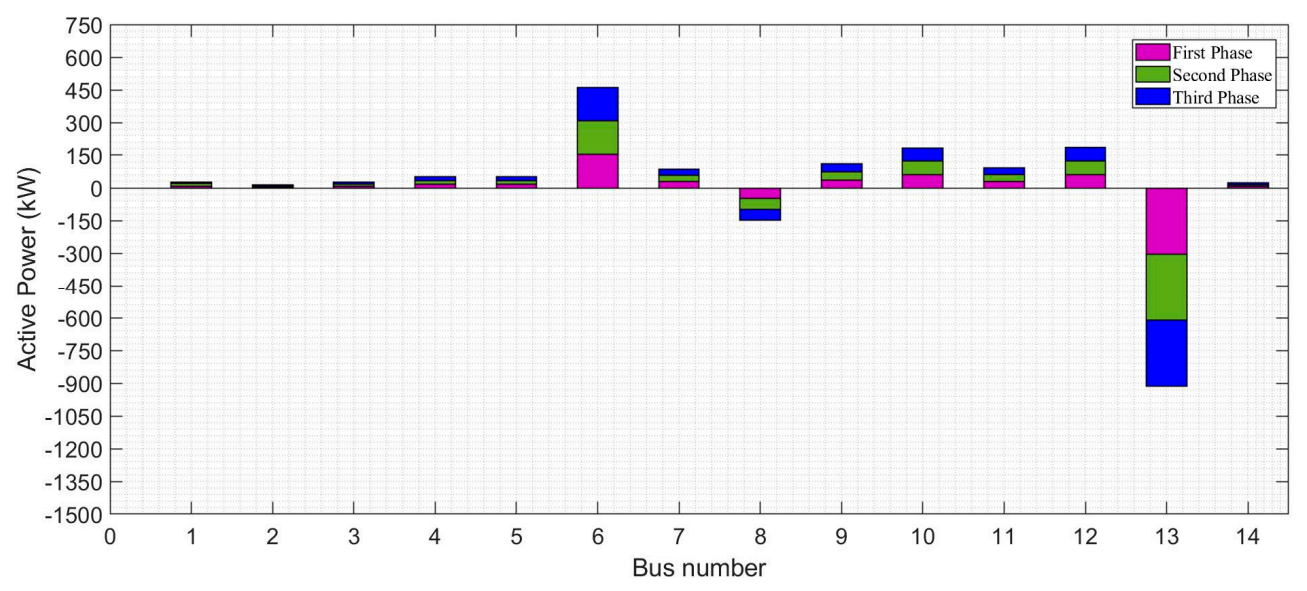

Figure 13. The minimum demand power balance.

Figure 14 illustrates the PR controller's output signal (a) and the error signal (b) that are produced during the 180-degree reference shift. The primary argument is that PR-controller has an output signal that is often less than one. As the pulse width modulation has an amplitude of one carrier, saturation is not achieved by the built PR controller in transitional and steady times. Figure 15a shows the magnitude response, and Figure 15b shows the phase response of designed combined resonant paths. 


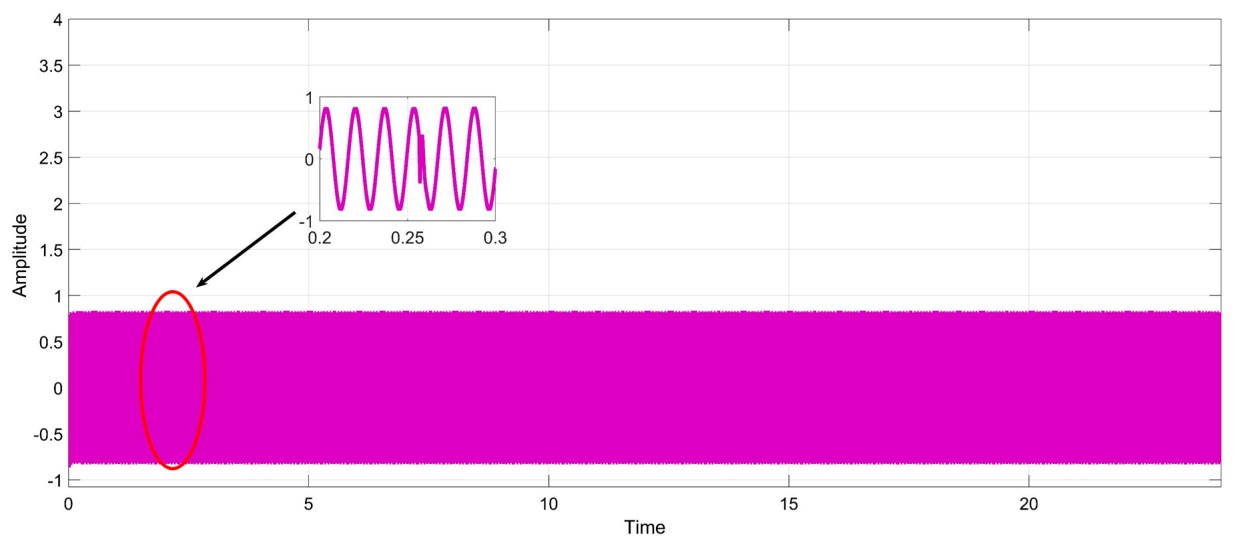

(a)

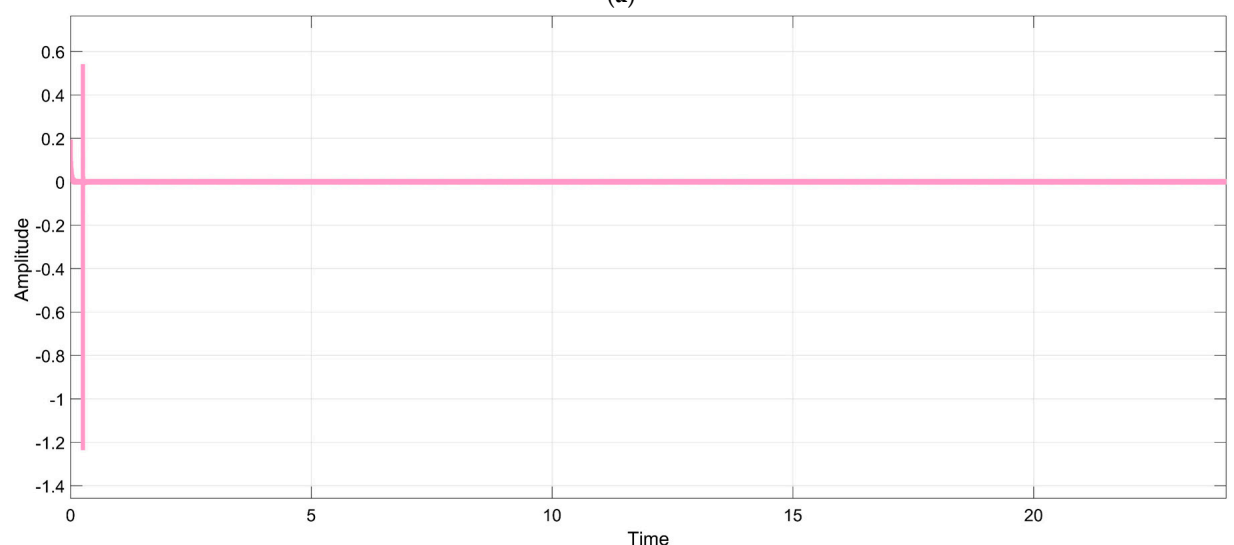

(b)

Figure 14. (a) The output of the PR controller, (b) error signal of the PR controller during the 180-degree reference change.

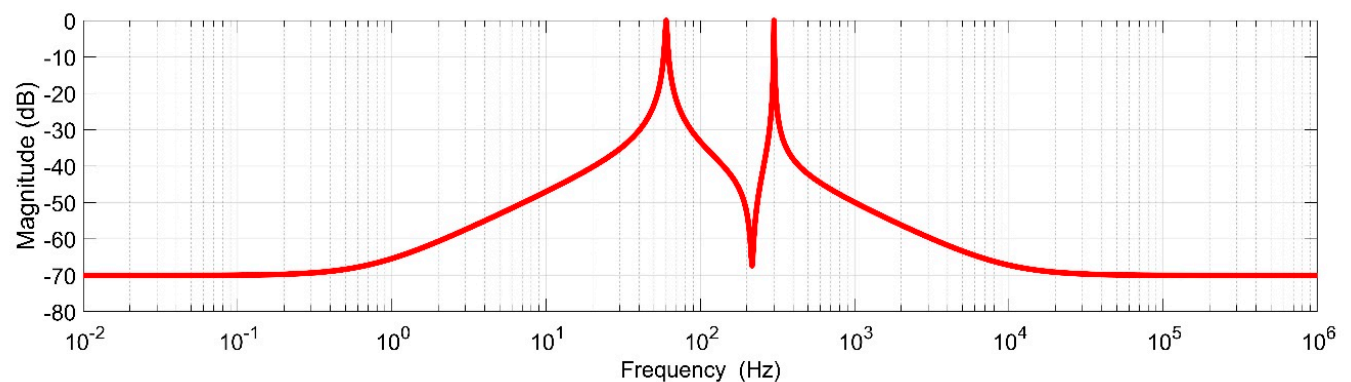

(a)

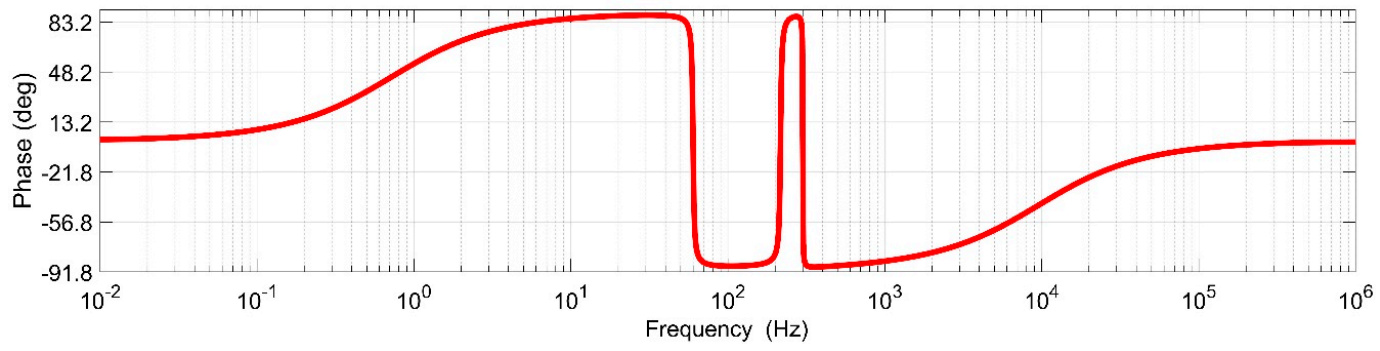

(b)

Figure 15. (a) Magnitude response, (b) phase response of designed combined resonant paths. 


\section{Analysis Reactive-Power Balance}

Figures 16 and 17 highlight system characteristics at the maximum and minimum demand levels, respectively. Bus-specific voltage profiles, reactive power balances, changes in voltage phase angles, are depicted in the abovementioned figures. In both situations, it can be observed that there is an association between reactive injection and the voltage increment at the bus, where the present power generation compensates for reactive powers. The reactive powers of systems are observed using Bus8 having diesel generators, and Bus13 having external reactive power. Nevertheless, as depicted in Figure 16, the maximum demand situation indicates the transfer of reactive power to buses 9 and 14 .

Specific to this scenario, the power flow direction indicates negative power at these buses. Tables 7 and 8 provide details specific to these situations. The analysis of reactive power compensation requires these crucial scenarios as the starting points to obtain voltage optimisation. Concerning maximum demand, the compensation values can be validated using an analysis of the contributions during minimum demand. Figure 17 highlights the voltage characteristics concerning the specified case. Values are appropriate, and for certain buses, they exceed one p.u. In such cases, analyses should be performed during reactive power injection increase to optimise maximum demand situations

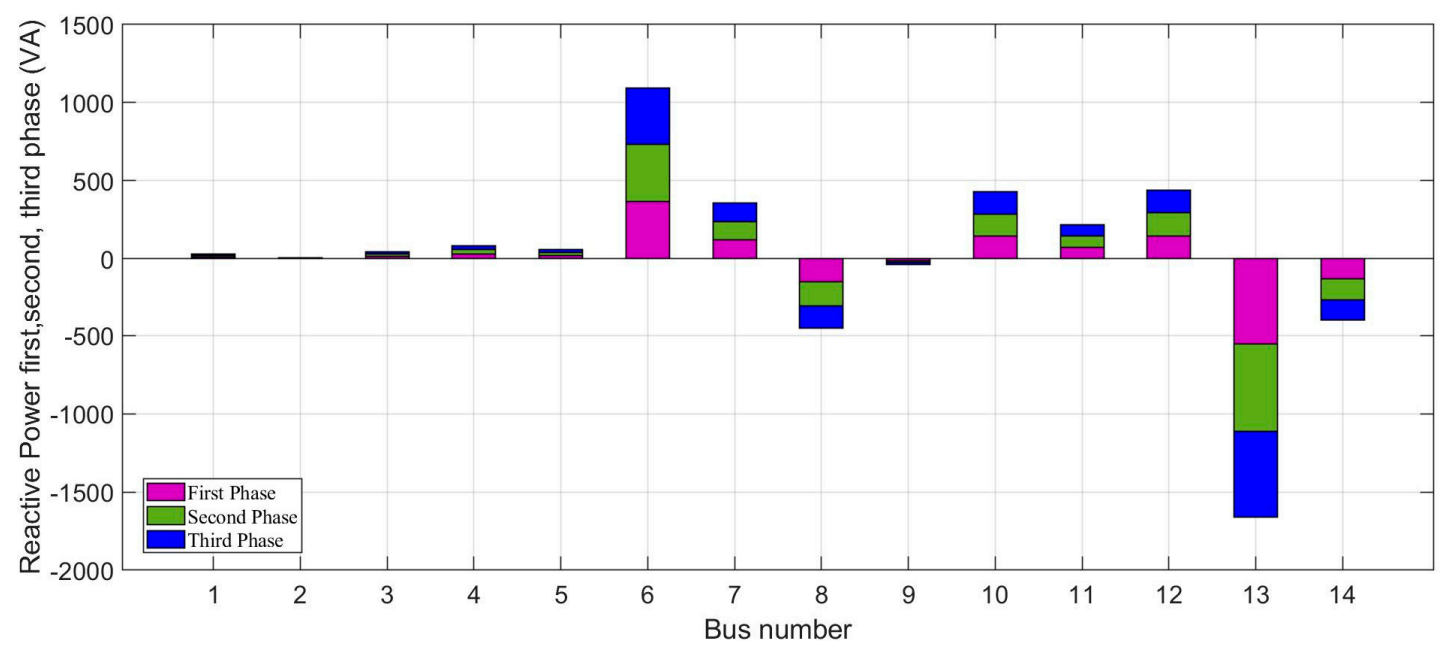

(a)

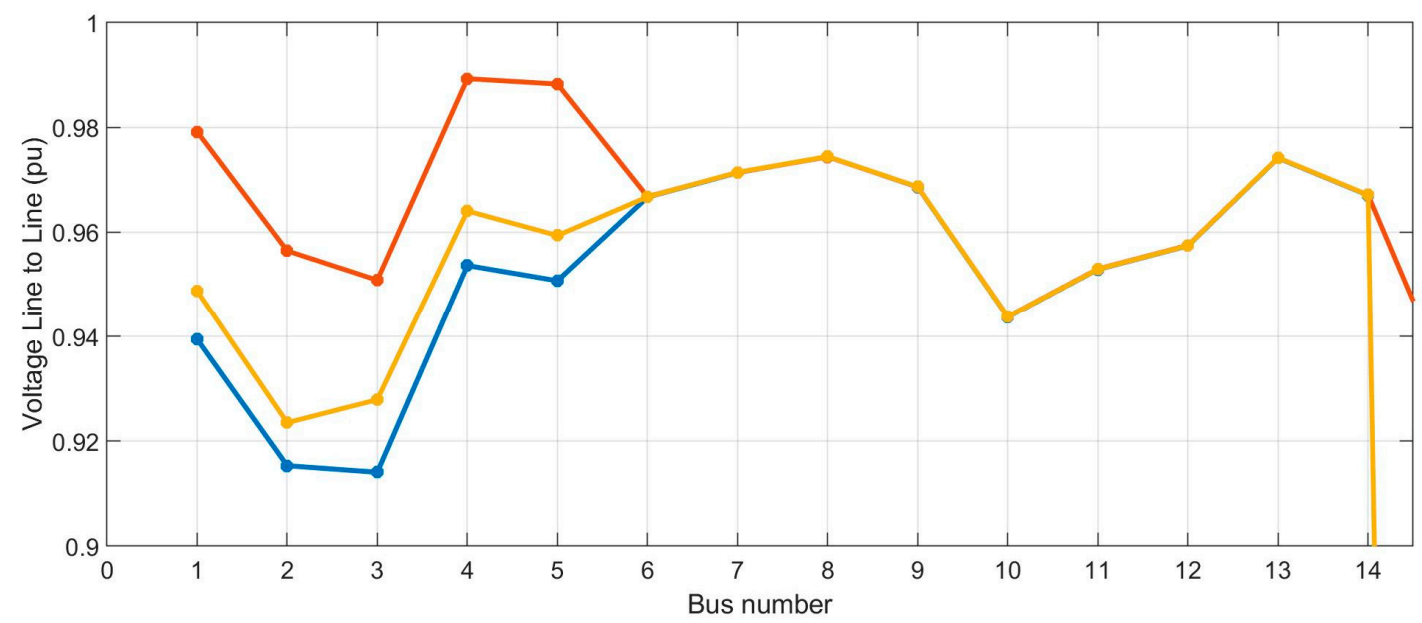

(b)

Figure 16. (a) The reactive power balance at maximum demand and7 (b) the voltage at maximum demand. 


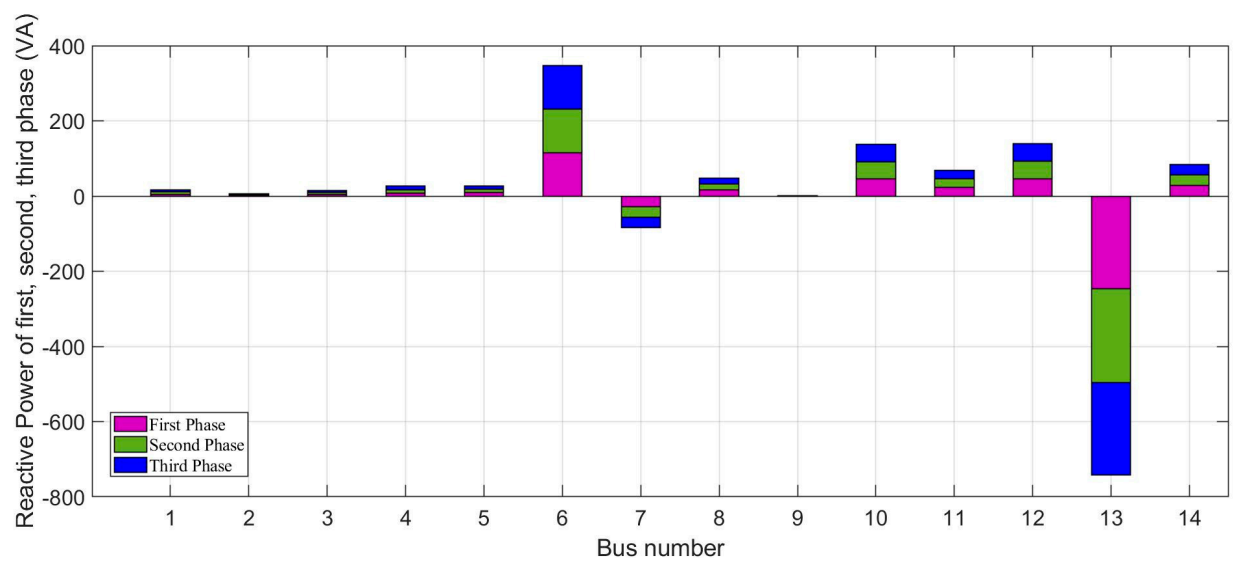

(a)

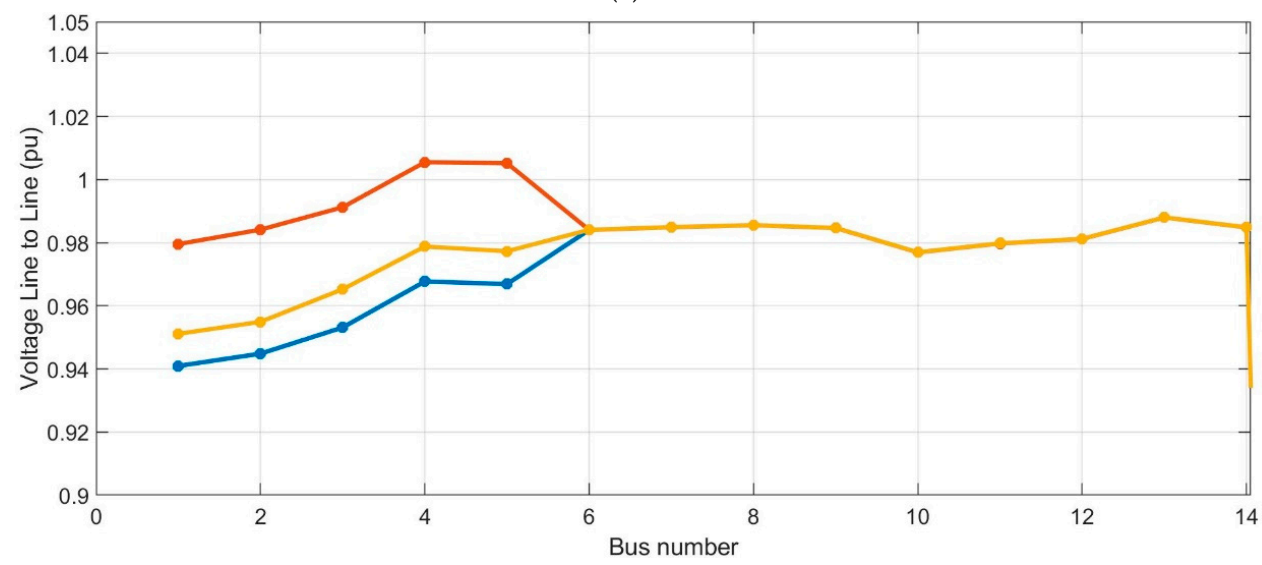

(b)

Figure 17. (a) The reactive power balance at minimum demand and (b) the voltage at minimum demand.

\section{Buss Power Factor}

The powers factors to any bus is one of the main variables to take into account when measuring the power flow of a device that needs compensation. Figures 18 and 19 show the power-factor in minimum and maximum demand scenarios for each system bus. Figure 19 demonstrates the scenario of high demand showing how bus 2 and bus 9 have a power factor of approximately 1 . It is because bus 2 is only involved with a maximum demand obtained from the DC microgrid.

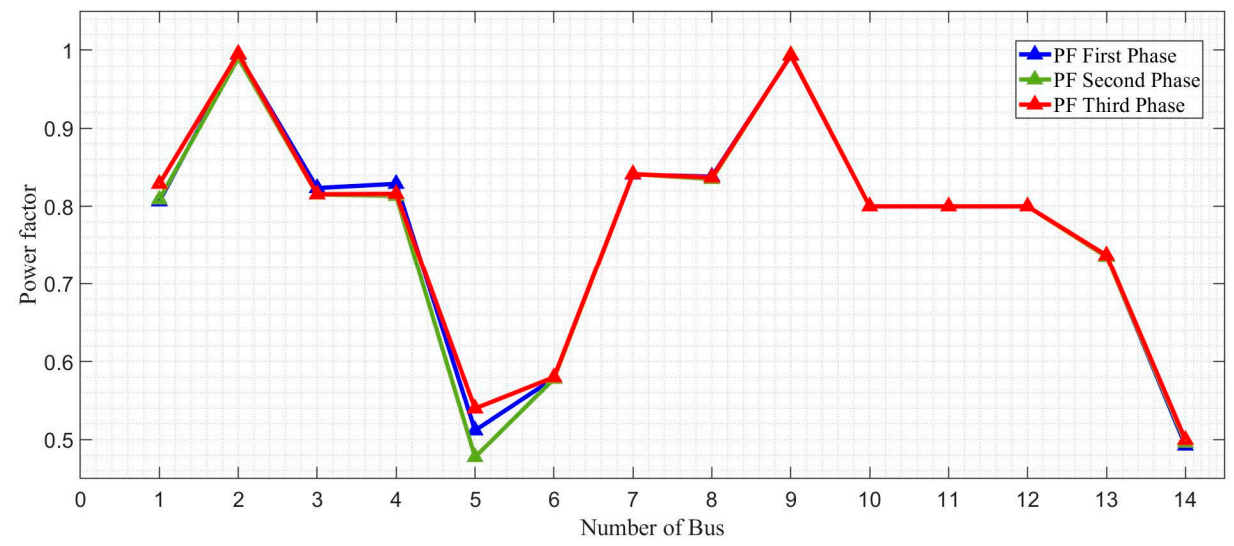

Figure 18. Maximum demand power-factor. 


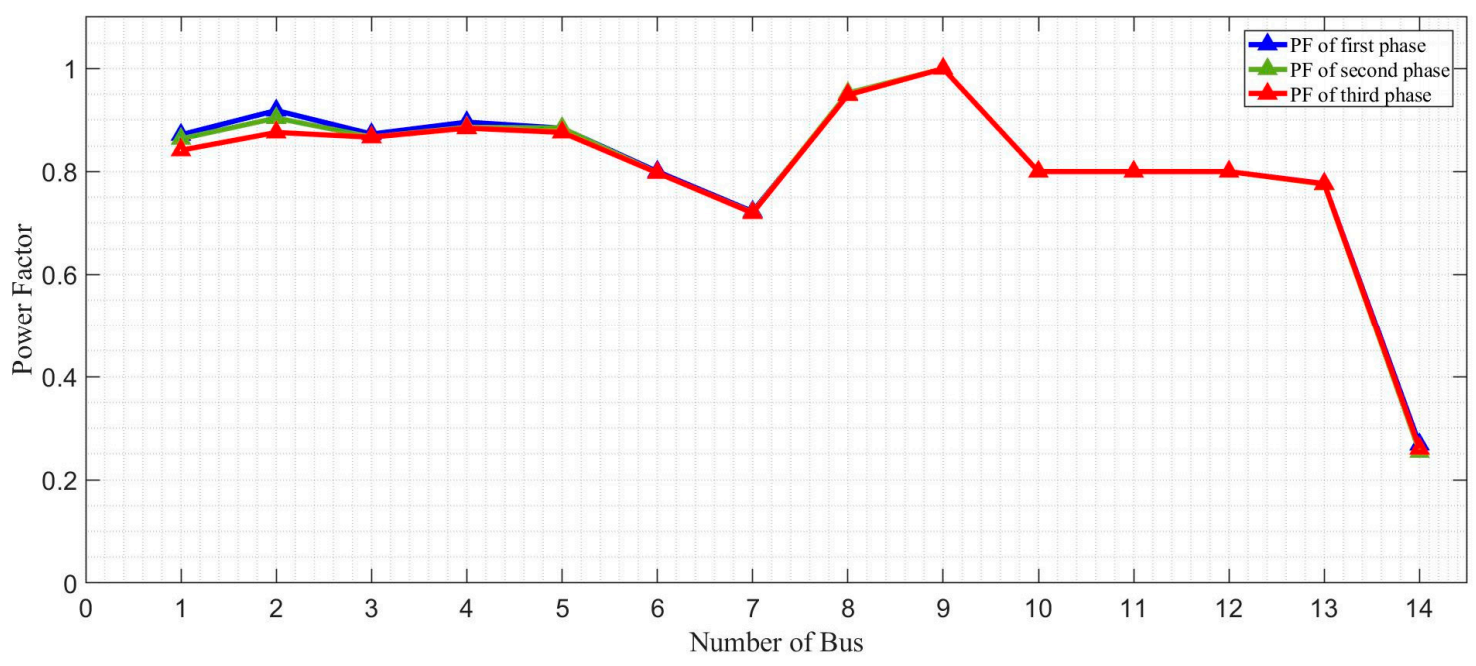

Figure 19. Minimum demand power-factor.

An important result is obtained by comparing the power factor for both scenarios (minimum and maximum demand). Most buses have a much better power factor than the maximum demand scenario under low demand conditions. The relationship of reactive power reduction for the maximum demand with the minimum demand scenario is the same as the reactive power reduction. The grid will continue to have the same power factor as the results of this analysis. However, the maximum demand is 0.73 , while the minimum demand is 0.77 .

The disparity in the power factors is shown by both situations in buses 5 and 6 . The losses of active powers in photovoltaic is the result of this phenomenon. This study identifies potential contradictions in the variable power element only in terms of the compensation of the active power contribution to an electrical system. When only the active power is injected, the grid sees a deteriorating power factor requiring more criteria to compensate for the system.

\section{Power Loss to Lines}

The active powers loss for the system was computed under both balanced and unbalanced currents. Equation (33) specifies the power loss concerning a State of Charge (SoC) using first line and second line [33-37]:

$$
\mathscr{P}_{a, \ell}=\left(\sum_{i=1}^{n}\left|\mathscr{I}_{i, a, \ell}\right|^{2}\right) \times\left(\mathscr{R}_{n}+\mathscr{R}_{\ell}\right)
$$

Figures 20 and 21 depict the phase loss for every line when the system is in minimum and maximum demand situations. It can be observed from the figures that the maximum loss occurs during low-voltage on the grid carrier feed line. Concerning every phase, the highest power loss of approximately $9.9 \mathrm{~kW}$ is present on line 7 (responsible for connecting buses 3 and 4); nevertheless, there is less distance. Figures 20 and 21 depict the active power losses happening on every phase under unbalanced loading. Such an imbalance in load is because of the low-voltage grid supplying single-phase loads. Figure 21 highlights that the maximum loss per phase is limited to $1.4 \mathrm{~kW}$. This level is significantly less compared to the maximum demand loss specific to every phase. 


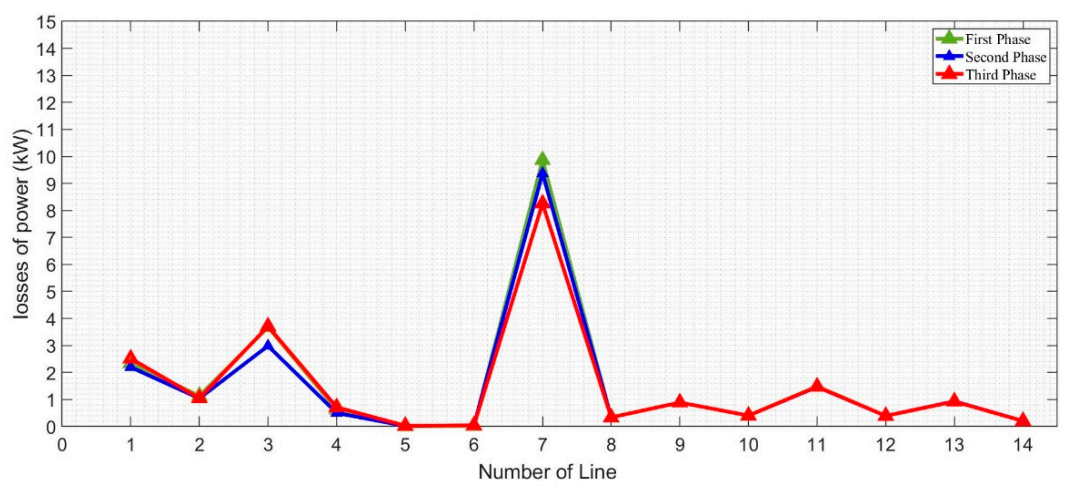

Figure 20. Maximum demand power losses per phase.

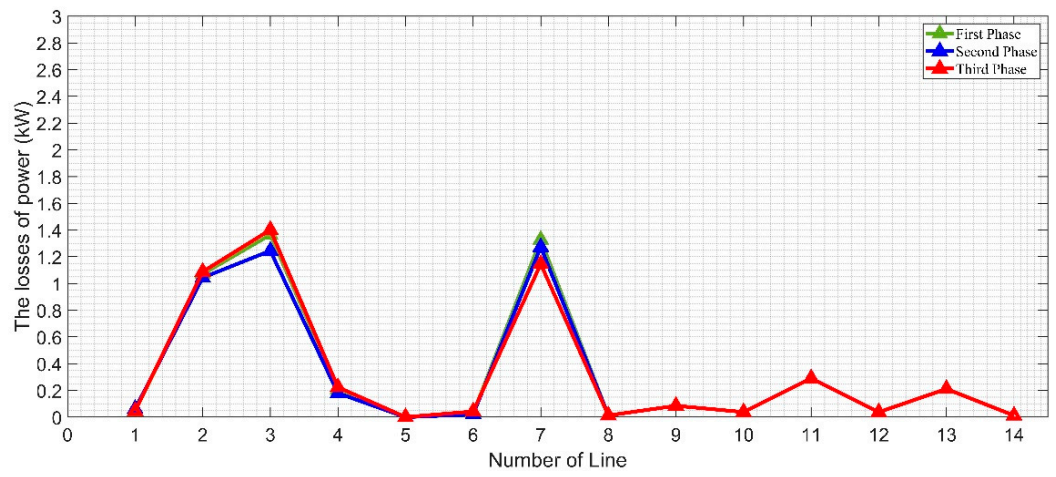

Figure 21. Minimum demand power losses per phase.

\section{Conclusions}

This paper presents a novel cooperative controller for smart hybrid AC/DC microgrid inverters using the IEEE 14 test feeder as the basis and with major modifications. Included in the proposed hybrid microgrid are a one-line diagram and the essential data for both the $13.8-\mathrm{kV}$ primary system and $0.22-\mathrm{kV}$ secondary system. The design process for a digital PR current controller within a GCI is also presented in this paper. The process is made up of a systematic list for the computation of the resonant and proportional gains and the digital resonant path coefficients. After using the proposed procedure based on the PR current controller design, the paper provided an analysis of the frequency domain in the fictitious $\mathrm{w}$-domain, which demonstrates that the proposed procedure satisfies the requirement of the GCI in current-controlled mode. Both a case study and a discussion illustrated the effectiveness of the design procedure, which makes it an appealing instrument for practical engineering. Two scenarios are included in the proposed system: the minimum power demand and the maximum power demand. For every scenario, the power flow results are published. All buses are equipped with their own measurement module. Calculation of the measurements related to the power quality, total harmonic distortion of voltage, and total harmonic distortion of current is performed, as well as its ability to calculate power factors and power line losses. Separate descriptions were given for the results gathered from the analysis of the two scenarios (maximum and minimum) based on the calculations by the proposed system, which allowed for a broader comprehension of the problem for every variable involved in the analysis of quality and efficiency of the power. Analysis of the existing competition for some variables was performed, particularly in the power factor. This is a result of the high penetration of photovoltaic generation, which intensifies the power factor experienced by the commercial entities offering the electric service in the mode linked to the grid. 
Author Contributions: B.N.A.: writing—original draft, software, methodology, and validation; B.H.J.: formal analysis, investigation, resources, writing-review and editing; W.I.: review and editing, M.D.E.: supervision, funding, writing-review and editing. All authors have read and agreed to the published version of the manuscript.

Funding: This research received no external funding.

Conflicts of Interest: The authors declare no conflict of interest.

\section{References}

1. Naji Alhasnawi, B.; Jasim, B.H.; Anvari-Moghaddam, A.; Blaabjerg, F. A New Robust Control Strategy for Parallel Operated Inverters in Green Energy Applications. Energies 2020, 13, 3480. [CrossRef]

2. Issa, W.; Sharkh, S.; Abusara, M. Hybrid Generators-based AC Microgrid Perfor-mance Assessment in Island Mode. IET Power Electron. 2019, 12, 1973-1980. [CrossRef]

3. Issa, W.R.M. Improved Control Strategies for Droop-Controlled Inverter-Based Microgrid, Doctor of Philosophy in Renewable Energy; University of Exeter: Exeter, UK, 2015.

4. Issa, W.R.; El Khateb, A.H.; Abusara, M.A.; Mallick, T.K. Control Strategy for Uninterrupted Microgrid Mode Transfer during Unintentional Islanding Scenarios. IEEE Trans. Ind. Electron. 2018, 65, 4831-4839. [CrossRef]

5. Al Badwawi, R.; Issa, W.R.; Mallick, T.K.; Abusara, M. Supervisory Control for Power Management of an Islanded AC Microgrid Using a Frequency Signalling-Based Fuzzy Logic Controller. IEEE Trans. Sustain. Energy 2019, 10, 94-104. [CrossRef]

6. Al-naemi, F.; Issa, W.; Ramadan, A.; Hall, J. Design and Modelling of Permanent Magnet Fault Current Limiter for Electrical Power Applications. In Proceedings of the 2018 53rd International Universities Power Engineering Conference (UPEC), Glasgow, UK, 4-7 September 2018. [CrossRef]

7. Issa, W.; Sharkh, S.M.; Albadwawi, R.; Abusara, M.; Mallick, T.K. DC link voltage control during sudden load changes in AC microgrid. In Proceedings of the 2017 IEEE 26th International Symposium on Industrial Electronics (ISIE), Edinburgh, UK, 19-21 June 2017. [CrossRef]

8. Xu, Q.; Xiao, J.; Wang, P.; Wen, C. A Decentralized Control Strategy for Economic Operation of Autonomous AC, DC, and Hybrid AC/DC microgrids. IEEE Trans. Energy Convers. 2017, 32, 1345-1355. [CrossRef]

9. Espín-Sarzosa, D.; Palma-Behnke, R.; Núñez-Mata, O. Energy Management Systems for Microgrids: Main Existing Trends in Centralized Control Architectures. Energies 2020, 13, 547. [CrossRef]

10. Pourbehzadi, M.; Niknama, T.; Aghaei, J.; Mokryani, G.; Shafie-khahcd, M.; Catalão, J.P. Optimal operation of hybrid AC/DC microgrids under uncertainty of renewable energy resources: A comprehensive review. Int. J. Electr. Power Energy Syst. 2019, 109, 139-159. [CrossRef]

11. Martin-Martínez, F.; Sanchez-Miralles, A.; Rivier, M. A Literature Review of Microgrids: A Functional Layer Based Classification. Renew. Sustain. Energy Rev. 2016, 62, 1133-1153. [CrossRef]

12. Nasr-Azadani, E.; Su, P.; Zheng, W.; Rajda, J.; Cañizares, C.; Kazerani, M. The Canadian Renewable Energy Laboratory: A testbed for microgrid. IEEE Electrif. Mag. 2020, 8, 49-60. [CrossRef]

13. Alhasnawi, B.N.; Jasim, B.H. A New Coordinated Control of Hybrid Microgrids with Renewable Energy Resources under Variable Loads and Generation Conditions. Iraqi J. Electr. Electron. Eng. 2020, 9, 345-364. [CrossRef]

14. Andishgar, M.H.; Gholipour, E.; Hooshmand, R.A. An Overview of Control Approaches of Inverter Based Microgrids in Islanding Mode of Operation. Renew. Sustain. Energy Rev. 2017, 80, 1043-1060. [CrossRef]

15. Liu, B.; Wu, W.; Zhou, C.; Mao, C. An AC-DC Hybrid Multi-Port Energy Router with Coordinated Control and Energy Management Strategies. IEEE Access 2019, 57, 109069-109082. [CrossRef]

16. Bai, W.; Sechilariu, M.; Locment, F. DC Microgrid System Modeling and Simulation Based on a Specific Algorithm for Grid-Connected and Islanded Modes with Real-Time Demand-Side Management Optimization. Appl. Sci. 2020, 10, 2544. [CrossRef]

17. Shan, Y.; Hu, J.; Chan, K.; Fu, Q.; Guerrero, J.M. Model Predictive Control of Bidirectional DC-DC Converters and AC/DC Interlinking Converters-A New Control Method for PV-Wind-Battery Microgrids. IEEE Trans. Sustain. Energy 2019, 26, 2513-2522. [CrossRef]

18. Qiu, H.; Gu, W.; Xu, Y.; Zhao, B. Multi-Time-Scale Rolling Optimal Dispatch for AC/DC Hybrid Microgrids with Day-Ahead Distributionally Robust Scheduling. IEEE Trans. Sustain. Energy 2018, 10, 1653-1663. [CrossRef] 
19. Bazmohammadi, N.; Tahsiri, A.; Guerrero, J.M. Stochastic Predictive of Multi-Microgrid Systems. IEEE Trans. Ind. Appl. 2019, 55, 5311-5319. [CrossRef]

20. Armghan, H.; Yang, M.; Armghan, A.; Alia, N.; Wang, M.Q. Design of integral terminal sliding mode controller for the hybrid AC/DC microgrids involving renewables and energy storage systems. Int. J. Electr. Power Energy Syst. 2020, 119, 105857. [CrossRef]

21. Yousefi, M.; Hajizadeh, A.; Soltani, M.N.; Hredzak, B. Predictive Home Energy Management System with Photovoltaic Array, Heat Pump and Plug-in Electric Vehicle. IEEE Trans. Ind. Inform. 2020, 34, 567-578. [CrossRef]

22. Zakzouk, N.E.; Abdelsalam, A.K.; Helal, A.A.; Williams, B.W. High Performance Single-Phase Single-Stage Grid-Tied PV Current Source Inverter Using Cascaded Harmonic Compensators. Energy 2020, 13, 380. [CrossRef]

23. Xie, B.; Guo, K.; Mao, M.; Zhou, L.; Liu, T.; Zhang, Q.; Hao, G. Analysis and Improved Design of Phase Compensated Proportional Resonant Controllers for Grid-Connected Inverters in Weak Grid. IEEE Trans. Energy Convers. 2020. [CrossRef]

24. Rasekh, N.; Hossein, M. LCL filter design and robust converter side current feedback control for grid-connected Proton Exchange Membrane Fuel Cell system. Int. J. Hydrogen Energy 2020, 45, 13055-13067. [CrossRef]

25. Basha, C.H.; Rani, C.; Brisilla, R.M.; Odofin, S. Mathematical Design and Analysis of Photovoltaic Cell Using MATLAB/Simulink. In Soft Computing for Problem Solving; Springer: Singapore, 2020; pp. 711-726. [CrossRef]

26. Sangwongwanich, A.; Blaabjerg, F. Mitigation of Interharmonics in PV Systems with Maximum Power Point Tracking Modification. IEEE Trans. Power Electron. 2019, 34, 8279-8282. [CrossRef]

27. Rakhshan, M.; Vafamand, N.; Khooban, M.H.; Blaabjerg, F. Maximum Power Point Tracking Control of Photovoltaic Systems. A Polynomial Fuzzy Model-Based Approach. IEEE J. Emerg. Sec. Power Electron. 2017, 6, 292-299. [CrossRef]

28. Subramaniyan, A.B.; Pan, R.; Kuitche, J.; TamizhMani, G. Quantification of Environmental Effects on PV Module Degradation: A Physics-Based Data-Driven Modeling Method. IEEE J. Photovolt. 2018, 8, 1289-1296. [CrossRef]

29. Hong, Y.Y.; Buay, P.M.P. Robust design of type-2 fuzzy logic-based maximum power point tracking for photovoltaics. Sustain. Energy Technol. Assess. 2020, 38, 100669. [CrossRef]

30. Fathima, A.H.; Palanisamy, K. Optimization in Microgrids with Hybrid Energy Systems-A Review. Renew. Sustain. Energy Rev. 2015, 45, 431-446. [CrossRef]

31. Hong, Y.Y.; Lai, Y.Z.; Chang, Y.R.; Lee, Y.D.; Lin, C.H. Optimizing Energy Storage Capacity in Islanded Microgrids Using Immunity-Based Multi objective Planning. Energies 2018, 11, 585. [CrossRef]

32. Wu, K.; Zhou, H. A Multi-Agent-Based Energy-Coordination Control System for Grid-Connected Large-Scale Wind-Photovoltaic Energy Storage Power Generation Units. Sol. Energy 2014, 57, 107-245. [CrossRef]

33. Ortiz, L.; Orizondo, R.; Águila, A.; González, J.W.; López, G.J.; Isaac, I. Hybrd AC/DC microgrd test system simulaton: Grid-connected mode. Heliyon 2019, 5, e2865. [CrossRef]

34. Busarello, T.D.C.; Pomilio, J.A.; Simoes, M.G. Design Procedur for a Digtal Proportonal Resonant Curent Controller in a Grid Conected Inverters. In Proceedings of the 2018 IEEE 4th Southern Power Electronics Conference (SPEC), Singapore, Singapore, 10-13 December 2018. [CrossRef]

35. Bacha, S.; Munteanu, I.; Bratcu, A.I. Power Electronic Converters Modeling and Control: With Case Studies. Springer Sci. Bus. Media 2013, 454, 454. [CrossRef]

36. Aguila, A.; Carrion, D.; Ortiz, L. Analysis of Power Losses in the Asymmetric Construction of Electric Distribution Systems. IEEE Lat. Am. Trans. 2015, 13, 2190-2194. [CrossRef]

37. Lam, C.-S.; Wang, L.; Ho, S.-I.; Wong, M.-C. Adaptive Thyristor-Controlled LC-hybrid Active Power Filter for Reactive Power and Current Harmonics Compensation with Switching Loss Reduction. IEEE Trans. Power Electron. 2016, 32, 7577-7590. [CrossRef]

(C) 2020 by the authors. Licensee MDPI, Basel, Switzerland. This article is an open access article distributed under the terms and conditions of the Creative Commons Attribution (CC BY) license (http://creativecommons.org/licenses/by/4.0/). 